\title{
Universiteit
}

Leiden

The Netherlands

\section{Molecular and functional characterization of the scavenger receptor CD36 in zebrafish and common carp}

Fink, I.R.; Benard, E.L.; Hermsen, T.; Meijer, A.H.; Forlenza, M.; Wiegertjes, G.F.

\section{Citation}

Fink, I. R., Benard, E. L., Hermsen, T., Meijer, A. H., Forlenza, M., \& Wiegertjes, G. F. (2015). Molecular and functional characterization of the scavenger receptor CD36 in zebrafish and common carp. Molecular Immunology, 63(2), 381-393.

doi:10.1016/j.molimm.2014.09.010

Version: $\quad$ Publisher's Version

License: $\quad$ Licensed under Article 25fa Copyright Act/Law (Amendment Taverne)

Downloaded from: https://hdl.handle.net/1887/3197041

Note: To cite this publication please use the final published version (if applicable). 


\title{
Molecular and functional characterization of the scavenger receptor CD36 in zebrafish and common carp
}

\author{
Inge R. Fink ${ }^{\mathrm{a}}$, Erica L. Benard ${ }^{\mathrm{b}}$, Trudi Hermsen ${ }^{\mathrm{a}}$, Annemarie H. Meijer ${ }^{\mathrm{b}}$, \\ Maria Forlenza ${ }^{a}$, Geert F. Wiegertjes ${ }^{\mathrm{a}, *}$ \\ a Cell Biology and Immunology Group, Wageningen Institute of Animal Sciences, Wageningen University, PO Box 338, 6700 AH Wageningen, \\ The Netherlands \\ ${ }^{\mathrm{b}}$ Institute of Biology, Leiden University, Einsteinweg 55, 2333 CC Leiden, The Netherlands
}

\section{A R T I C L E I N F O}

\section{Article history:}

Received 20 June 2014

Received in revised form

11 September 2014

Accepted 17 September 2014

Available online 11 October 2014

\section{Keywords:}

CD36

Scavenger receptor

Zebrafish

Carp

Immune function

\begin{abstract}
A B S T R A C T
CD36 is a scavenger receptor which has been studied closely in mammals where it is expressed by many different cell types and plays a role in highly diverse processes, both homeostatic and pathologic. It is among other things important in the innate immune system, in angiogenesis, and in clearance of apoptotic cells, and it is also involved in lipid metabolism and atherosclerosis. Recently, in the cephalochordate amphioxus a primitive CD36 family member was described, which was present before the divergence of CD36 from other scavenger receptor B family members, SCARB1 and SCARB2. Not much is known on the Cd36 molecule in teleost fish. We therefore studied Cd36 in both zebrafish and common carp, two closely related cyprinid fish species. Whereas a single $c d 36$ gene is present in zebrafish, carp has two $c d 36$ genes, and all show conserved synteny compared to mammalian CD36. The gene expression of carp cd36 is high in brain, ovary and testis but absent in immune organs. Although in mammals CD36 expression in erythrocytes, monocytes and macrophages is high, gene expression studies in leukocyte subtypes of adult carp and zebrafish larvae, including thrombocytes and macrophages provided no indication for any substantial expression of $c d 36$ in immune cell types. Surprisingly, analysis of the cd36 promoter region does show the presence of several binding sites for transcription factors known to regulate immune responses. Overexpression of carp cd36 locates the receptor on the cell surface of mammalian cell lines consistent with the predicted topology of cyprinid Cd36 with a large extracellular domain, two transmembrane domains, and short cytoplasmic tails at both ends. Gene expression of $c d 36$ is down-regulated during infection of zebrafish with Mycobacterium marinum, whereas knockdown of cd36 in zebrafish larvae led to higher bacterial burden upon such infection. We discuss the putative role for Cd36 in immune responses of fish in the context of other members of the scavenger receptor class B family.
\end{abstract}

(C) 2014 Elsevier Ltd. All rights reserved.

\section{Introduction}

Scavenger receptors are soluble or membrane-associated molecules which have in common the ability to bind chemically modified lipoproteins or other poly-anionic ligands (Plüddemann et al., 2007). Each molecule additionally binds to other ligands, and scavenger receptors are thus functionally diverse. They have

Abbreviations: CD36, cluster of differentiation 36; dpf, days post fertilization; dpi, days post injection; hpf, hours post fertilization; LDL, low density lipoprotein; LTA, lipoteichoic acid; PBL, peripheral blood leukocytes; RT-PCR, reverse transcription polymerase chain reaction; RT-qPCR, real-time quantitative polymerase chain reaction; SCARB, scavenger receptor class B; TLR, Toll-like receptor.

* Corresponding author. Tel.: +31317 482732.

E-mail address: geert.wiegertjes@wur.nl (G.F. Wiegertjes). been grouped together into eight classes $(\mathrm{A}-\mathrm{H})$ where members within a class display structural homology. However, between the eight classes the scavenger receptors are structurally very different. CD36 is a member of the scavenger receptor class B family, which also contains scavenger receptor class B member 1 and 2 (SCARB1 and SCARB2) (Calvo and Vega, 1993; Calvo et al., 1995). SCARB1 is important in lipid metabolism as a receptor mediating cholesterol transfer to and from high density lipoprotein HDL (Brundert et al., 2005; Chadwick and Sahoo, 2013). SCARB2 (also referred to as lysosomal integral membrane protein-2, LIMP-2) is required for the normal biogenesis and maintenance of lysosomes and endosomes and as such plays a role in various human diseases (Gonzalez et al., 2014). CD36 is an integral membrane glycoprotein with two transmembrane domains, a large extracellular loop containing multiple glycosylation sites, and two short intracellular tails. In mammals, CD36 is expressed by many different cell types such as platelets, 
monocytes and macrophages, endothelial cells and hepatocytes, and CD36 seems to play a role in highly diverse processes, both homeostatic and pathologic (Febbraio et al., 2001). Mammalian CD36 was originally identified as a macrophage receptor for oxidized LDL (Endemann et al., 1993), but its ligand-binding ability is very extensive and encompasses endogenous as well as exogenous ligands (reviewed in Silverstein and Febbraio, 2009). Among other molecules, CD36 recognizes microbial diacylglycerides such as macrophage-activating lipopeptide 2 from Mycoplasma pneumoniae (MALP-2) and lipoteichoic acid from Staphylococcus aureus and acts as a co-receptor for these molecules together with Toll-like receptor (TLR) 2/6 heterodimers (Hoebe et al., 2005; Stuart et al., 2005). As a receptor recognizing exogenous pathogen-associated molecular patterns (PAMPs), CD36 is acknowledged as a pattern recognition receptor (PRR) important in innate immunity.

CD36 orthologs have been described in many vertebrate species such as human, mouse (Endemann et al., 1993), rat (Abumrad et al., 1993), cow (Greenwalt et al., 1990) and chicken (Shu et al., 2011). Ancestral homologs are also found in invertebrate species such as C. elegans (Means et al., 2009), sea urchin and fruit fly, and a recent study reported several homologs in amphioxus, a basal chordate (Zhang et al., 2013). Presumably due to amphioxusspecific gene duplication events there are five $c d 36$ paralogs in this species. These genes are thought to represent the primitive form of scavenger receptor class B before the divergence of CD36, SCARB1 and SCARB2. One of the amphioxus genes was cloned and studied in more detail: its expression was up-regulated in the gills upon feeding and down-regulated during fasting. In addition, studies in Atlantic salmon and rainbow trout have focused on fatty acid transport proteins including Cd36 and described gene expression changes regulated by insulin, fasting and dietary composition (Sanchez-Gurmaches et al., 2011, 2012; Torstensen et al., 2011). This suggests a conservation of the role of SCARB family members in at least nutritional control and/or lipid metabolism. Contrary to the mammalian species, knowledge of the immune function of $\mathrm{Cd} 36$ in teleost fish is lacking.

In mammals, there is evidence of CD36 interaction with preformed Toll-like receptor TLR2-TLR6 heterodimers, where CD36 recognizes specific lipids or lipoproteins and brings the ligand to the TLRs. Ligand/receptor clusters localize within lipid rafts of the plasma membrane, after which intracellular signalling and phagocytosis is initiated (Triantafilou et al., 2006). The intracellular signalling goes via MyD88 and a series of phosphorylation and ubiquitination events of cytosolic proteins, leading to activation of the transcription factor NFKB and expression of immune related genes (Akira and Takeda, 2004). Of interest, out of eight accessory molecules classified in mammals as important mediators of ligand delivery and/or recognition and required for TLR function (Lee et al., 2012) only four molecules, including CD36, seem to have clear orthologs in fish genomes (Pietretti et al., 2013). Given our interest in the function of TLRs (Pietretti and Wiegertjes, 2014) among which Tlr2 (Ribeiro et al., 2010), we studied Cd36 in zebrafish and common carp, two closely related cyprinid fish species, taking advantage of the complementary tools available for these two species to achieve a more thorough understanding of the function of $\mathrm{Cd} 36$ in teleost fish.

We characterize for the first time in detail Cd36 of zebrafish and two Cd36 molecules of common carp finding a molecular structure consistent with mammalian CD36. Phylogenetic analysis as well as a synteny approach allowed us to confidently designate the cyprinid molecules as homologs of the mammalian CD36. Gene expression was studied in tissues and leukocyte subtypes, indicating a complete absence of $c d 36$ basal gene expression in immune organs and leukocytes of adult carp. However, knockdown of $c d 36$ in zebrafish embryos by a morpholino approach and subsequent Mycobacterium marinum infection indicated a role for
Cd36 in controlling bacterial burden. We discuss the possibility that the division of functions between the $\mathrm{Cd} 36$ family members $\mathrm{Cd} 36$, Scarb1 and Scarb2, all of which are present in teleosts, may not be exactly the same as in their mammalian counterparts.

\section{Materials and methods}

\subsection{Animals}

European common carp (Cyprinus carpio carpio L.) were reared in the central fish facility Carus, at Wageningen University, Wageningen, Netherlands. Fish were kept at $23^{\circ} \mathrm{C}$ in recirculating UV-treated tap water and fed pelleted dry food (Sniff, Soest, Germany) daily. R3xR8 carp are the hybrid offspring of a cross between fish of Polish origin (R3 strain) and Hungarian origin (R8 strain) (Irnazarow, 1995). Carp were between 9 and 11 months old at the start of the experiments. All studies were performed with approval from the local animal welfare committee (DEC) of Wageningen University.

Zebrafish were handled in compliance with the local animal welfare regulations, maintained according to standard protocols (zfin.org), and culture was approved by the local animal welfare committee (DEC) of Leiden University. Embryos from the zebrafish $\mathrm{AB} / \mathrm{TL}$ line were used for the infection experiments. Embryos were grown at $28.5^{\circ} \mathrm{C}$ in egg water $(60 \mu \mathrm{g} / \mathrm{mL}$ Instant Ocean sea salts). For the duration of bacterial injections and stereo fluorescence imaging embryos were kept under anaesthesia in egg water containing $200 \mu \mathrm{g} / \mathrm{mL}$ tricaine methane sulfonate (Sigma-Aldrich, St. Louis, MO, USA). Embryos used for stereo fluorescence imaging were kept in egg water containing 0.003\% 1-phenyl-2-thiourea (SigmaAldrich) to prevent melanisation which can produce background fluorescence during imaging. For fluorescence activated cell sorting (FACS) isolation of macrophages and neutrophils from zebrafish larvae, the transgenic lines $\mathrm{Tg}(\mathrm{mpeg} 1: m$ Cherry-F) UMSF001 (Bernut et al., 2014) and $\operatorname{Tg}(m p x: e g f p)^{i 114}$ (Renshaw et al., 2006) were used, respectively.

\subsection{Organ isolation}

Carp aged 9-11 months were euthanized with $0.3 \mathrm{~g} / \mathrm{L}$ tricaine methane sulfonate (TMS, Crescent Research Chemicals, Phoenix, AZ, USA) buffered with $0.6 \mathrm{~g} / \mathrm{L} \mathrm{NaHCO}_{3}$. Carp were bled from the caudal vein using a needle and syringe containing cRPMI medium (RPMI 1640 with 25 mM HEPES, (Lonza, Basel, Switzerland) adjusted to an osmolality of $280 \mathrm{mOsm} / \mathrm{kg}$ with sterile water) containing $50 \mathrm{U} / \mathrm{mL}$ heparin (Leo Pharma, Ballerup, Denmark), $50 \mathrm{U} / \mathrm{mL}$ penicillin G (Sigma-Aldrich), and $50 \mu \mathrm{g} / \mathrm{mL}$ streptomycin sulphate (Sigma-Aldrich). For isolation of peripheral blood leukocytes (PBL), the heparinized blood was centrifuged at $100 \times \mathrm{g}$ for $5 \mathrm{~min}$ at $4{ }^{\circ} \mathrm{C}$ and then another $5 \mathrm{~min}$ at $300 \times \mathrm{g}$. The buffy coat was collected, carefully layered on Ficoll-Paque PLUS (GE Healthcare, Little Chalfont, UK) and centrifuged at $800 \times \mathrm{g}$ for $25 \mathrm{~min}$ at $4{ }^{\circ} \mathrm{C}$ without brake. The leukocyte layer was collected and washed twice with CRPMI. The obtained PBL were stored at $-80^{\circ} \mathrm{C}$ until used for RNA isolation. After bleeding the fish, the organs of interest were aseptically removed and immediately frozen in liquid nitrogen and stored at $-80^{\circ} \mathrm{C}$ until used for RNA isolation.

Zebrafish embryos for RNA isolation were snap-frozen in liquid nitrogen and stored at $-80^{\circ} \mathrm{C}$.

\subsection{Isolation of leukocyte subtypes}

Carp leukocyte subtypes were isolated by density gradient separation and/or magnetic cell sorting using specific antibodies as 
described before for thrombocytes (Rombout et al., 1996), thymocytes (Stolte et al., 2008), granulocytes (Forlenza et al., 2008), B cells (Koumans-van Diepen et al., 1995; Secombes et al., 1983), and macrophages (Romano et al., 1998). In short, PBL or single-cell suspensions derived from carp organs were incubated with primary mouse monoclonal antibody: WCL-6 for thrombocytes (from blood), TCL-BE8 for neutrophils (from mid kidney), WCI-12 for B cells (from blood), and WCL-15 for monocytes/macrophages (from spleen). After incubation and washing, cells were stained with phycoerythrin (PE)-conjugated goat anti-mouse secondary antibody. After washing and counting of cells, magnetic beads (anti-PE MicroBeads, Miltenyi Biotec GmbH, Bergisch Gladbach, Germany) were added and allowed to bind, before washing and magnetic separation on LS Midi Columns using a MidiMACS Separator (Miltenyi Biotec).

For isolation of leukocytes from $\mathrm{Tg}$ (mpeg1:mCherry-F) UMSF001 and $\operatorname{Tg}(m p x: e g f p)^{i 114}$ zebrafish, larvae at 5-6 days post fertilization (dpf) were dissociated according to Covassin et al. (2006). In short, anaesthetized embryos were dechorionated using pronase treatment, rinsed in calcium-free Ringer solution, followed by digestion with $0.25 \%$ trypsin and $1 \mathrm{mM}$ EDTA. The obtained cell suspension was centrifuged, rinsed with PBS and resuspended in Leibovitz medium L15 without phenol red, $1 \%$ foetal calf serum, $0.8 \mathrm{mM}$ $\mathrm{CaCl}_{2}$, penicillin $50 \mathrm{U} / \mathrm{mL}$ and streptomycin $0.05 \mathrm{mg} / \mathrm{mL}$. The single cell suspension was subjected to FACS at room temperature using a FACSAria (Becton Dickinson) with the BD FACSDiva software version 5.0.3 and a Coherent Sapphire solid state laser $488 \mathrm{~nm}$ with $13 \mathrm{~mW}$ power. The fluorescence-positive and negative cell fractions were collected in medium as above but with $10 \%$ foetal calf serum.

\subsection{RNA isolation}

Total RNA from carp organs and leukocytes was extracted using the RNeasy Mini kit according to the manufacturer's protocol (Qiagen, Venlo, Netherlands) including on-column DNase treatment with the RNase-free DNase set (Qiagen). Final elution was performed with $30 \mu \mathrm{L}$ nuclease-free water. The integrity of the RNA was determined by agarose gel electrophoresis and the RNA quality and concentrations were assessed spectrophotometrically by measuring the absorbance at $260 \mathrm{~nm}$ and $280 \mathrm{~nm}$ (Nanodrop, Thermo Scientific, Waltham, MA, USA). RNA from M. marinum-infected zebrafish was isolated at $4 \mathrm{dpi}$ as described in Stockhammer et al. (2009). RNA from zebrafish larval leukocytes was isolated directly after FACS sorting using the RNAqueous-Micro Kit (Ambion, Carlsbad, CA, USA). Zebrafish RNA quality was checked by lab-on-a-chip analysis with an Agilent Bioanalyzer 2100 using the RNA 6000 Pico kit (Agilent, Santa Clara, CA, USA). RNA was stored at $-80^{\circ} \mathrm{C}$ until use.

\section{5. cDNA synthesis}

Prior to cDNA synthesis, $500 \mathrm{ng}-2 \mu \mathrm{g}$ of carp total RNA was subjected to an additional DNase treatment by using DNase I Amplification Grade (Invitrogen, Carlsbad, CA, USA). Synthesis of cDNA was performed with Invitrogen's SuperScript III Reverse Transcriptase, according to the manufacturer's instructions. As control for genomic contamination, for each sample a reaction without SuperScript III Reverse Transcriptase was performed. cDNA samples were diluted 25 times in nucleasefree water before use as templates in real-time quantitative PCR experiments. For zebrafish samples, cDNA synthesis was performed as described previously (Stockhammer et al., 2009), using iScript reverse transcriptase (Bio-Rad Laboratories, Hercules, CA, USA). Zebrafish cDNA was diluted 10 times before further use.

\subsection{Real-time quantitative PCR}

Real-time quantitative PCR (RT-qPCR) on samples from carp was performed in a Rotor-Gene 6000 with a 72-well rotor (Corbett Research, Qiagen) with the ABsolute QPCR SYBR Green Mix (Thermo Scientific) as detection chemistry. All primers were from Eurogentec (Liège, Belgium) and were used as forward and reverse primer mix at a $2.1 \mu \mathrm{M}$ final concentration. Master-mix for each RT-qPCR run was prepared as follows: per reaction, $2 \mu \mathrm{L}$ of primer stock was mixed with $7 \mu \mathrm{L}$ of SYBR Green. To $9 \mu \mathrm{L}$ of master-mix, $5 \mu \mathrm{L}$ of diluted cDNA was added in a $0.1 \mathrm{~mL}$ tube. The following amplification program was used: one denaturation step of $15 \mathrm{~min}$ at $95^{\circ} \mathrm{C}$; followed by 40 cycles of a three-step amplification $(15 \mathrm{~s}$ at $95^{\circ} \mathrm{C}$ for denaturation, $20 \mathrm{~s}$ at $60^{\circ} \mathrm{C}$ for annealing, $20 \mathrm{~s}$ at $72^{\circ} \mathrm{C}$ for elongation). Then a short hold for $1 \mathrm{~min}$ at $60^{\circ} \mathrm{C}$, before a melting analysis starting from $60^{\circ} \mathrm{C}$ and increasing to $90^{\circ} \mathrm{C}$ in $0.5^{\circ} \mathrm{C}$ steps with $5 \mathrm{~s}$ waiting. Fluorescence acquisition was performed at the end of each cycle and during the waiting steps of the melting analysis.

RT-qPCR data were analysed by Rotor-Gene 6000 Series Software 1.7. The melting temperature and profile of the melting curves were used to validate the specificity of the amplification. The gene expression was analysed using the average amplification efficiency for each primer pair and the take-off value of each sample (as derived from the Comparative Quantitation Analysis of the Rotor-Gene 6000 Series Software 1.7). The relative gene expression was calculated as the average amplification efficiency to the power of the take-off value. The gene expression of the housekeeping gene $40 S$ ribosomal protein S11 was used to normalize the data.

RT-qPCR analysis of zebrafish samples was performed as described in Stockhammer et al. (2009). Reactions contained $10 \mu \mathrm{L}$ of $2 \times$ iQ SYBR Green Supermix (Bio-Rad Laboratories), 5 pmol of each primer, and $5 \mu \mathrm{L}$ diluted cDNA in a total of $20 \mu \mathrm{L}$. All reactions were performed with biological triplicates and technical duplicates. Data from zebrafish leukocytes were normalised to the expression of eukaryotic translation initiation factor $4 A$, isoform $1 B$ (eif4), whereas data from $M$. marinum-infected zebrafish embryos were normalized to peptidylprolyl isomerase Alike (ppial). For analysis purposes an amplification efficiency of 2 was assumed.

The sequences of primers used in this study are given in Table 1.

\subsection{Cloning full-length cd36a from common carp}

Carp head kidney leukocytes were obtained essentially as described previously (Verburg-van Kemenade et al., 1994). RNA was isolated as described above and then used as template in reverse-transcription PCR using the LongRange 2Step RT-PCR kit (Qiagen). Reverse transcription was done with an oligo-dT primer and the subsequent PCR was done with gene-specific primers (CycaCD36_FW1 and CycaCD36_RV3, see Table 1) whose sequence was based on preliminary information from the carp genome. Semi-nested PCR was then performed with the Expand High Fidelity PCR System (Roche Diagnostics, Basel, Switzerland) with primers CycaCD36_FW1 and CycaCD36_RV2 (see Table 1). The PCR product was subsequently cloned into pGEM-T Easy (Promega, Madison, WI, USA) and transformed into E. coli JM109 competent cells (Promega). Eight clones were sequenced using the ABI prism BigDye Terminator Cycle Sequencing Ready Reaction kit (Applied Biosystems, Foster City, CA, USA) and analysed using a 3730 DNA Analyzer. Sequence data were analysed with Sequencher version 4.10 (Gene Codes, Ann Arbor, MI, USA) and aligned with Clustal Omega (http://www.ebi.ac.uk/Tools/msa/clustalo/). A clone with the consensus sequence was used for further studies. 
Table 1

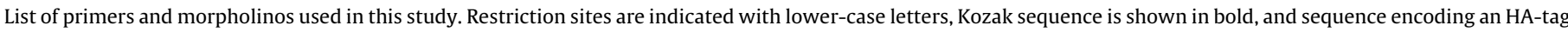
is underlined.

\begin{tabular}{|c|c|c|}
\hline Oligo name & Sequence $5^{\prime} \rightarrow 3^{\prime}$ & Purpose \\
\hline CycaCD36_FW1 & GCTGCTGCTCGCCATC & Cloning of carp $c d 36 a$ \\
\hline CycaCD36_RV3 & GTTTTACTGAAATTGTGCTGACATAC & Cloning of carp $c d 36 a$ \\
\hline CycaCD36_RV2 & CCACAGTACGACCACATAATG & Semi-nested PCR for cloning of carp cd36a \\
\hline CD36_pcDNA3_FW & ACGAggatccAACATGGCATACCCATACGATGTTCCAGATTACGCTATGACCTGCTGTGATCTGAAATG & Cloning of carp $c d 36 a$ \\
\hline CD36_pcDNA3_RV & CATGctcgagACAATGAAGATTTTTTTTGTTATTGC & Cloning of carp $c d 36 a$ \\
\hline CD36_qFW1 & CGGGACTTTAGCATTTGAC & RT-qPCR of carp cd36a \\
\hline CD36_qRV1 & AGTGAAGTTATCATTGAAGGTG & RT-qPCR of carp cd36a \\
\hline CD36b_qFW2 & GCTGATTGGTCGGATGGAGT & RT-qPCR of carp $c d 36 b$ \\
\hline CD36b_qRV2 & GAAGTTTGGTATTTTTCGGTTTCA & RT-qPCR of carp $c d 36 b$ \\
\hline CD36_qFW2 & САССТTCAATGATAACTTCACTT & RT-qPCR of carp cd36a \\
\hline CD36_qRV2 & AGCGTTGGATGAGCAAG & RT-qPCR of carp cd36a \\
\hline CD36_qFW3 & GACAGATGGTTCCTCCTTC & RT-qPCR of carp $c d 36 a$ and $c d 36 b$ \\
\hline CD36_qRV3 & TTCCCTTCAGGTCAACAG & RT-qPCR of carp $c d 36 a$ and $c d 36 b$ \\
\hline CD36_qFW4 & GGGCTCATCACAGGGAC & RT-qPCR of carp cd36a \\
\hline CD36_qRV4 & TTGGCGTGTCTACAGACG & RT-qPCR of carp $c d 36 a$ \\
\hline CD36_qFW5 & GACCTGCTGTGATCTGAAATG & RT-qPCR of carp $c d 36 a$ and $c d 36 b$ \\
\hline CD36_qRV5 & GTCCCGTTTTCCAACACTG & RT-qPCR of carp $c d 36 a$ and $c d 36 b$ \\
\hline CD36_qFW6 & GTGAACCATCGCTGAGT & RT-qPCR of carp $c d 36 a$ and $c d 36 b$ \\
\hline CD36_qRV6 & GTCAACAGTTCCСTCATACTC & RT-qPCR of carp $c d 36 a$ and $c d 36 b$ \\
\hline 40S_FW & CCGTGGGTGACATCGTTACA & RT-qPCR of carp 40 S ribosomal protein $\mathrm{S} 11$ \\
\hline 40S_RV & TCAGGACATTGAACCTCACTGTCT & RT-qPCR of carp 40 S ribosomal protein S11 \\
\hline zf_cd36_qFW2 & CACAGGCAAAGATGACATT & RT-qPCR of zebrafish cd36 \\
\hline zf_cd36_qRV2 & CGGGTGGAAAGAGGAAC & RT-qPCR of zebrafish $c d 36$ \\
\hline eif4a1b_FW & TTCAGAAACTCAGTACTAGCATACA & RT-qPCR of zebrafish eif $4 a 1 b$ \\
\hline eif4a1b_RV & GTGACATCCAACACCTCTGC & RT-qPCR of zebrafish eif $4 a 1 b$ \\
\hline ppial_FW & ACACTGAAACACGGAGGCAAAG & RT-qPCR of zebrafish ppial \\
\hline ppial_REV & CATCCACAACCTTCCCGAACAC & RT-qPCR of zebrafish ppial \\
\hline MO1-CD36_e2i2 & CTATGAGGCCACAAATATTACCTGT & Zebrafish morpholino knockdown \\
\hline MO2-CD36-e3i3 & TTTGAAATACATACTGCGACAGCAA & Zebrafish morpholino knockdown \\
\hline MO-FW & TGCTTGGCGGAATCCTCATC & RT-PCR to verify zebrafish knockdown \\
\hline MO-RV & TCGGATAAGCCAATCTGCCAG & RT-PCR to verify zebrafish knockdown \\
\hline
\end{tabular}

\subsection{Bioinformatics}

The nucleotide sequence of zebrafish cd36 is available at Ensembl (ENSDARG00000032639). We obtained the coding sequence of carp cd36a after cloning, and the carp cd36b coding sequence is predicted based on genome sequence data (Bioproject PRJNA73579) (Henkel et al., 2012). In the present manuscript, to distinguish zebrafish from carp cd36, the genes are denoted as Cyprinus carpio (cc) or Danio rerio ( $d r)$ cd36 with labelling $a$ or $b$ for the two carp cd36. Exon-intron structure was studied by multiple alignments and open reading frame predictions (FGENESH at http://linux1.softberry.com/berry.phtml?topic=fgenesh\&group= programs\&subgroup=gfind, and GENSCAN at http://genes.mit.edu/ GENSCAN.html), and exon-intron structure was visualized using WormWeb (http://www.wormweb.org/exonintron). Nucleotide sequences were translated into protein sequence using the EMBLEBI tool (http://www.ebi.ac.uk/Tools/st/) and these were aligned with Clustal Omega (http://www.ebi.ac.uk/Tools/msa/clustalo/). Molecular weights were calculated with ProtParam (http://web. expasy.org/protparam/). Transmembrane regions were predicted using TMHMM Server v. 2.0 (http://www.cbs.dtu.dk/ services/TMHMM/) and $N$-glycosylation sites were predicted with NetNGlyc v. 1.0 (http://www.cbs.dtu.dk/services/NetNGlyc/). $O$-glycosylation sites were predicted using NetOGlyc v. 4.0 (http://www.cbs.dtu.dk/services/NetOGlyc/). Synteny analysis was performed on the basis of sequence information from Ensembl release 74 (http://www.ensembl.org/). The multiple sequence alignment for the phylogenetic tree was made with ClustalX 2.1 (Larkin et al., 2007) and the tree was constructed using the Neighbour Joining method with the number of bootstrap trials set to 10,000 , also using ClustalX 2.1. The phylogenetic tree was subsequently visualized with MEGA6 and displayed with the moderately related zebrafish scavenger receptor Scarf1 as the root. Amino acid identity and similarity between $\mathrm{Cd} 36$ proteins was calculated with the software MatGAT 2.0. The transcriptional start site for zebrafish $c d 36$ was determined by Cap Analysis Gene Expression (CAGE) analysis. MatInspector (http://www.genomatix.de/) was used to predict the presence of various vertebrate transcription factor binding sites in the promoter regions of human, mouse, chicken and zebrafish cd36.

\section{9. cd36a-mCherry expression plasmid}

The gene encoding the fluorescent protein mCherry was cloned into pcDNA3 using the BamHI and Xbal sites. An Xhol site and a short linker sequence of 15 nucleotides encoding the amino acids GGSGG was placed upstream of the mCherry sequence. Subsequently, the full-length carp cd36a sequence was modified from the above-mentioned pGEM-T Easy construct to include sequence to encode an HA-tag at the N-terminus, and to remove the stop codon, using primers CD36_pcDNA3_FW and CD36_pcDNA3_RV (see Table 1). The modified cccd36a was then cloned between the BamHI site and the newly created Xhol site in pcDNA3, thus creating a fusion of $c c c d 36 a-m C h e r r y$ in pcDNA3. Isolation of highly pure plasmid DNA suitable for transfection was performed with the S.N.A.P. MidiPrep Kit (Invitrogen) according to the manufacturer's instructions.

\subsection{Subcellular localization of carp Cd36a}

Human embryonic kidney 293 (HEK) cells were cultured at $37^{\circ} \mathrm{C}$ at $5 \% \mathrm{CO}_{2}$ in DMEM (Gibco, Carlsbad, CA, USA) supplemented with $10 \%$ foetal bovine serum (Gibco), $2 \mathrm{mM}$ L-glutamine (Merck, Darmstadt, Germany), 50U/mL penicillin G (Sigma-Aldrich), and $50 \mu \mathrm{g} / \mathrm{mL}$ streptomycin sulphate (Sigma-Aldrich). HEK cells were seeded directly on untreated glass cover slips, $4.5 \times 10^{4}$ cells each. The following day, cells were transfected with $2 \mu \mathrm{g}$ cccd36amCherry-pcDNA3 or mCherry-pcDNA3 using jetPRIME (Polyplus 
Transfection, Illkirch, France) according to the manufacturer's instructions at a $1: 2$ ratio of plasmid:transfection reagent.

The Epithelioma papulosum cyprini (EPC) cell line, which is an adherent cell type derived from fathead minnow, was cultured at $27^{\circ} \mathrm{C}$ at $5 \% \mathrm{CO}_{2}$ in RPMI 1640 (Lonza) supplemented with $10 \%$ foetal bovine serum, $2 \mathrm{mM} \mathrm{L}$-glutamine, $50 \mathrm{U} / \mathrm{mL}$ penicillin $\mathrm{G}$, and $50 \mu \mathrm{g} / \mathrm{mL}$ streptomycin sulphate. EPC cells were seeded on untreated glass cover slips in six-well plates, $1 \times 10^{6}$ cells/well, and allowed to adhere. EPC cells were transfected the following day with $2 \mu \mathrm{g} c c c d 36 a$-mCherry-pcDNA3 or mCherry-pcDNA3 using FuGENE HD Transfection Reagent (Promega) according to the manufacturer's instructions at a 1:3.5 ratio of plasmid:transfection reagent.

Three days after transfecting HEK and EPC cells with carp cd36a-mCherry-pcDNA3 or mCherry-pcDNA3, the cover slips were carefully washed with HBSS, fixed for $20 \mathrm{~min}$ at room temperature with $4 \%$ paraformaldehyde, washed with HBSS and stained with wheat germ agglutinin-Alexa Fluor 488 conjugate (Molecular Probes, Invitrogen) for $15 \mathrm{~min}$ at room temperature, before final washing with HBSS and mounting with Vectashield (Vector Laboratories, Burlingame, CA, USA).

Cells were visualized with a Zeiss LSM-510 (Zeiss, Oberkochen, Germany) confocal laser scanning microscope with a PlanApochromat $63 \times / 1.4$ oil immersion objective. Green fluorescent signal (Alexa Fluor 488) was excited with a $488 \mathrm{~nm}$ argon laser and detected using a band-pass filter (505-550 nm). Red fluorescence (mCherry protein) was excited with a $543 \mathrm{~nm}$ helium-neon laser and detected using a long-pass filter $(585 \mathrm{~nm})$. Image processing was performed with ImageJ (http://imagej.nih.gov/ij/).

\subsection{Morpholino knockdown}

Morpholino oligonucleotides (Gene Tools, Philomath, OR, USA) were diluted to the desired concentration in $1 \times$ Danieau buffer $\left(58 \mathrm{mM} \mathrm{NaCl}, 0.7 \mathrm{mM} \mathrm{KCl}, 0.4 \mathrm{mM} \mathrm{MgSO}_{4}, 0.6 \mathrm{mM} \mathrm{Ca}\left(\mathrm{NO}_{3}\right)_{2}\right.$, $5.0 \mathrm{mM}$ HEPES; pH 7.6) containing $1 \%$ phenol red (Sigma-Aldrich) and $1 \mathrm{~nL}$ was injected into the yolk at the 1-2 cell stage using a Femtojet injector (Eppendorf, Hamburg, Germany). For knockdown of cd36, two morpholinos were used, one targeting the exon 2-intron 2 splice junction (cd36 Mo1: 5'CTATGAGGCCACAAATATTACCTGT3', $0.2 \mathrm{mM}$ ), and the other targeting the exon 3 -intron 3 splice junction (cd36 Mo2: 5'TTTGAAATACATACTGCGACAGCAA3', $0.6 \mathrm{mM}$ ). As a control, the standard control morpholino from Gene Tools was used at the same concentrations as the corresponding cd36 morpholino. Knockdown of $c d 36$ with both morpholinos was verified at $1 \mathrm{dpf}$ by RT-PCR with the SuperScript ${ }^{\circledR}$ One-Step RT-PCR System (Invitrogen). Whole embryo RNA isolation was performed as described in Stockhammer et al. (2009) and 50 ng of DNAse treated (Invitrogen) RNA template was used for the RT-PCR reaction. RT-PCR primers for $c d 36$ knockdown verification were MO-FW and MO-RV, whose sequence is given in Table 1 . The following adjustments were made to the PCR settings: $56^{\circ} \mathrm{C}$ for $30 \mathrm{~s}$ for the annealing step of the PCR amplification with 35 cycles. To verify that cd36 knockdown did not affect leukocyte development an L-plastin immunostaining was performed as described (Mathias et al., 2007).

\subsection{M. marinum infection}

Mycobacterium marinum infections were performed using the wildtype Mma20 strain expressing mCherry in a pSMT3 vector (van der Sar et al., 2004). Embryos were staged at 24 hours post fertilization (hpf) by morphological criteria and manually dechorionated. Bacteria were prepared and injected into the blood circulation at $28 \mathrm{hpf}$ and plated during injections to confirm the number of injected colony forming units (cfu) (Benard et al., 2012). At 4 days post injection (dpi) the uninfected and infected embryos were
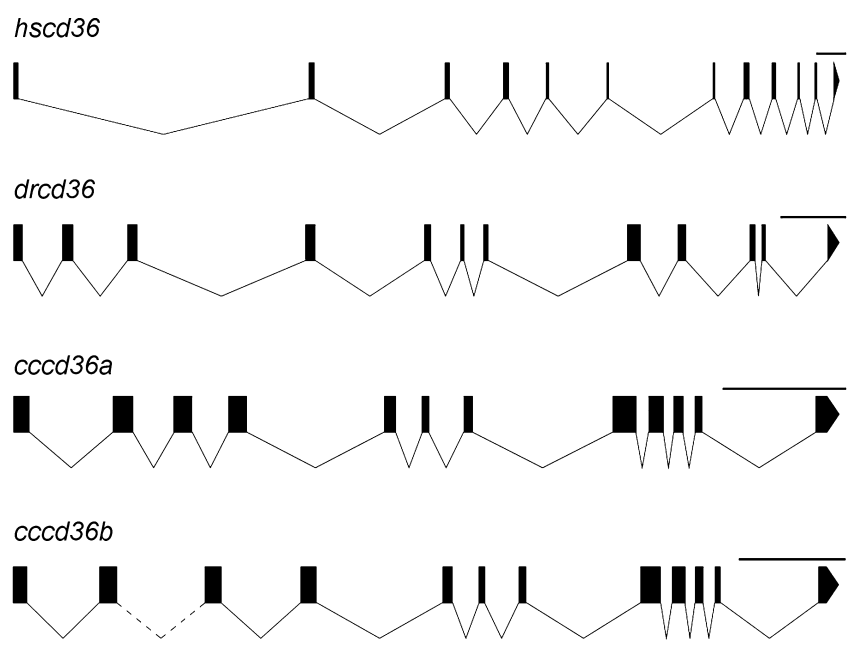

Fig. 1. Exon-intron structure of the $c d 36$ genes of human, zebrafish and carp. The exon-intron structure is shown for human (hscd36 Homo sapiens ENST00000309881), zebrafish (drcd36 Danio rerio ENSDART00000050753), and carp (cccd36a Cyprinus carpio Scaffold 349; cccd36b Cyprinus carpio Scaffolds 102854 and 15047). Exons are shown as boxes, introns as lines. Only coding exons are shown. Intron 2 of $c c c d 36 b$ is composed of sequence from Scaffolds 102,854 and 15,047 , which could not be precisely joined in the current assembly of the carp genome; this is indicated by the dotted line. Scale bar represents $1000 \mathrm{bp}$.

imaged with a stereo fluorescence microscope, and RNA was isolated for subsequent gene expression analysis. Knockdown with morpholino 1 was repeated four times with 174 morphants and 135 control embryos and the infection phenotype was confirmed with knockdown using morpholino 2 with 35 morphants and 60 control embryos. Fluorescence images were taken with a Leica MZ16FA stereo fluorescence microscope equipped with a DFC420 C digital colour camera. Overlay images of bright field and fluorescence stereomicroscopy were made in Fiji. M. marinum pixel count values were calculated using dedicated pixel quantification software (Stoop et al., 2011; Nezhinsky et al., 2012). All data for $M$. marinum pixel count (mean $\pm S E M$ ) were analysed using unpaired, two-tailed $t$-tests for comparisons between two groups (ns, no significant difference; $\left.{ }^{*} p<0.05 ;{ }^{* *} p<0.01 ;{ }^{* * *} p<0.001\right)$.

\section{Results}

\subsection{Identification of cyprinid cd36 genes}

We identified a single cd36 gene in zebrafish (ENSDARG00000032639) and two cd36 genes in common carp (Bioproject PRJNA73579). BLAST analyses in the zebrafish and carp genomes did not identify additional $c d 36$ genes. Furthermore, the presence of two genes in carp versus a single gene in zebrafish is very common, considering the additional whole genome duplication event that has taken place in carp compared to zebrafish (Henkel et al., 2012).

All three cyprinid $c d 36$ genes are composed of 12 exons and 11 introns, similar to the coding parts of the human $c d 36$ gene (Fig. 1). The full-length sequences ( $\operatorname{drcd36}, \operatorname{ccc} 336 a$ and $c c c d 36 b$ ) have open reading frames ranging from 1398 to $1410 \mathrm{bp}$ encoding for proteins of 465-469 aa with predicted molecular weights of 51.6-52.1 kDa. All three cyprinid molecules are predicted to be integral membrane glycoproteins with two transmembrane domains, a large extracellular loop and two short intracellular tails, one at the $\mathrm{N}$ - and one at the C-terminus (Fig. 2). The extracellular part is predicted to contain multiple $\mathrm{N}$-glycosylation sites as is the case for mammalian Cd36 (see Fig. 2). Furthermore, there are several conserved cysteines of which six are located in the extracellular part and two in the N-terminal intracellular tail. By similarity to the human Cd36 


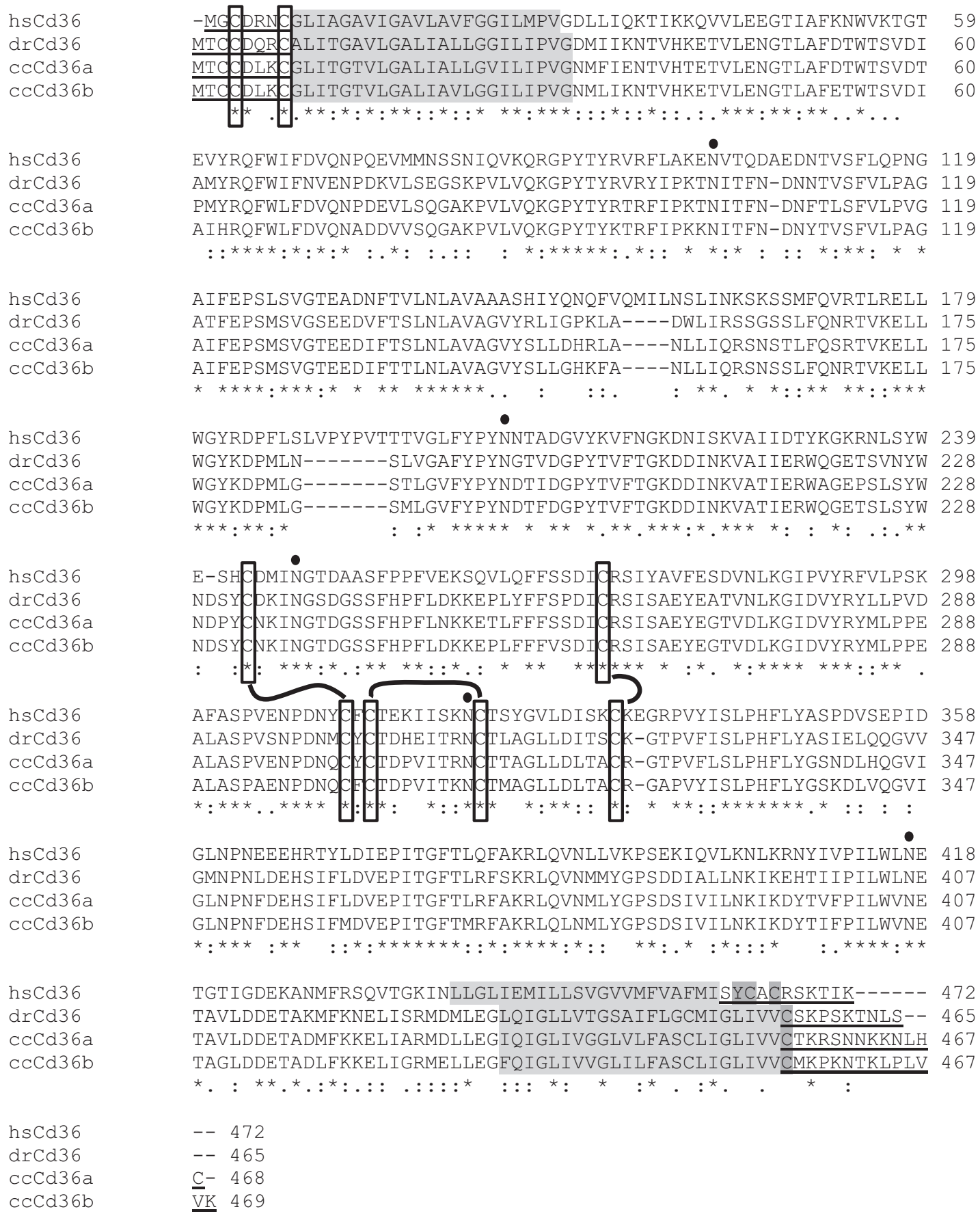

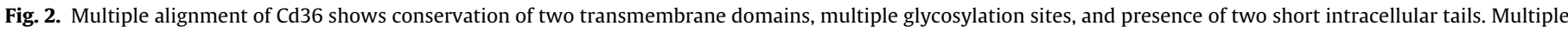

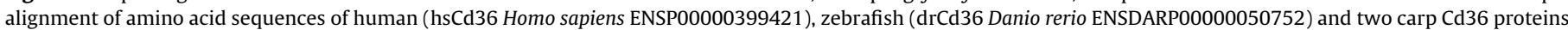

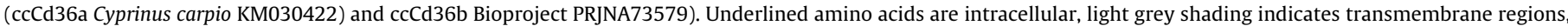

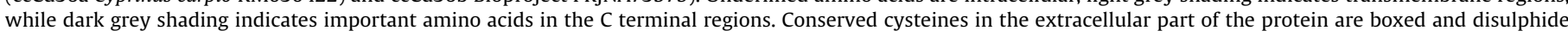
bonds are schematically shown. Conserved $\mathrm{N}$-glycosylation sites are indicated with black dots above the sequence.

protein, the six extracellular cysteines form disulphide bonds as follows: 243-311, 272-333, and 313-322 (human numbering). The two cysteines in the $\mathrm{N}$-terminal tail are known to be palmitoylated in the human Cd36 protein (Tao et al., 1996), acting as tethers to the plasma membrane and localizing the protein to lipid rafts. Also these amino acids are conserved in the cyprinid molecules. Although the above-mentioned conservation of structural characteristics could point at a conservation of function, the C-terminal tail appears less conserved and the alignment in this region is weak.
There are three amino acids in the C-terminus of the human protein which are important for the function, namely Y463, C464, and C466 (human numbering, dark grey shading in Fig. 2). The two cysteines are palmitoylated similar to the cysteines in the N-terminal tail, and the tyrosine is potentially a site of phosphorylation. Both Y463 and C464 are important for phagocytosis of bacteria and for subsequent signalling via TLR2/6, leading to NFKB activation and cytokine production (Stuart et al., 2005). The cyprinid Cd36 molecules lack a tyrosine in the C-terminal tail, and they only have a single 
cysteine (C456, cyprinid numbering, dark grey shading in Fig. 2). In conclusion, cyprinid Cd36 molecules are integral membrane glycoproteins with two transmembrane domains, a large extracellular loop and two short intracellular tails, similar to mammalian Cd36.

\subsection{Phylogenetic analysis}

An amino acid sequence alignment indicates a high degree of similarity, not only among the cyprinid Cd36 proteins (88.7-93\%) but also between cyprinid and other fish species, chicken, xenopus and mammalian Cd36 proteins (all $>70 \%$; Table 2 ). Also percentages of identity are very high with human to fish amino acid identities ranging from 50.8 to $52.3 \%$. This indicates that the molecule has been well conserved during evolution. The amphioxus $\mathrm{Cd} 36$ protein stands out as being most different from all the other proteins with identities around $35 \%$ only.

Phylogenetic analysis was performed on amino acid sequences of multiple Cd36 and Scarb molecules (Fig. 3). A moderately related scavenger receptor, zebrafish Scarf1, was used as an outgroup to root the phylogenetic tree. The overall topology of the phylogenetic tree shows that the Cd36, Scarb1 and Scarb2 molecules form separate clusters. In this study we have identified a putative Cd36 of Atlantic salmon, a sequence we obtained by performing a BLAST search in salmon whole genome shotgun sequences using the zebrafish Cd36 sequence. This putative Cd36 molecule conforms with the phylogenetic tree contrary to the rainbow trout $\mathrm{Cd} 36$, whose position in the tree suggests it should be renamed into Scarb2. The ancestral amphioxus Cd36 seems to be closer related to the Scarb1 family. Amongst the remaining Cd36 molecules, the tetrapods (mammalian, bird and amphibian molecules) form one cluster and all the fish molecules branch out in a separate cluster. Zebrafish Cd36 and the two carp Cd36 molecules cluster together as expected from the high identities found between these. Bootstrap values are high in the entire tree with only a single exception, namely the split between stickleback and platyfish/medaka Cd36 molecules. Overall, the phylogenetic tree highlights the close relationship of all the teleost Cd36 proteins, visibly separate from the teleost Scarb1 and Scarb2 molecules and from the tetrapod proteins.

\subsection{Synteny analysis}

Conservation of synteny was investigated by comparing the genomic regions immediately up- and down-stream of human, mouse, chicken and xenopus $c d 36$ with the genomic regions upand down-stream of $c d 36$ in a number of fish species with an annotated genome, including zebrafish and common carp (Fig. 4). Human, mouse and chicken genomes contain a block of five genes: magi2, gnai1, gnat3, cd36, and sema3c. This block is fairly conserved in the other species with the exception of xenopus and fish genomes lacking the gnat3 gene. For carp, although the scaffolds are limited in length, the analysis does confirm conservation of synteny with sema3c downstream of $c d 36 a$ and $c d 36 b$, and a partial gnai1 sequence upstream of $c d 36 a$. Overall, analysis of the genes adjacent to $c d 36$ in cyprinid fish indicates conserved synteny between teleost $c d 36$ and non-teleost $c d 36$.

\subsection{Promoter analysis}

In addition to synteny analysis we also studied in detail the transcription factor binding sites in the promoter region of zebrafish cd36 and compared this to human, mouse and chicken (Supplementary Fig. 1). The transcriptional start site has not been determined for either of the carp cd36 genes, so promoter analysis was not performed for these. The putative transcriptional start site for zebrafish

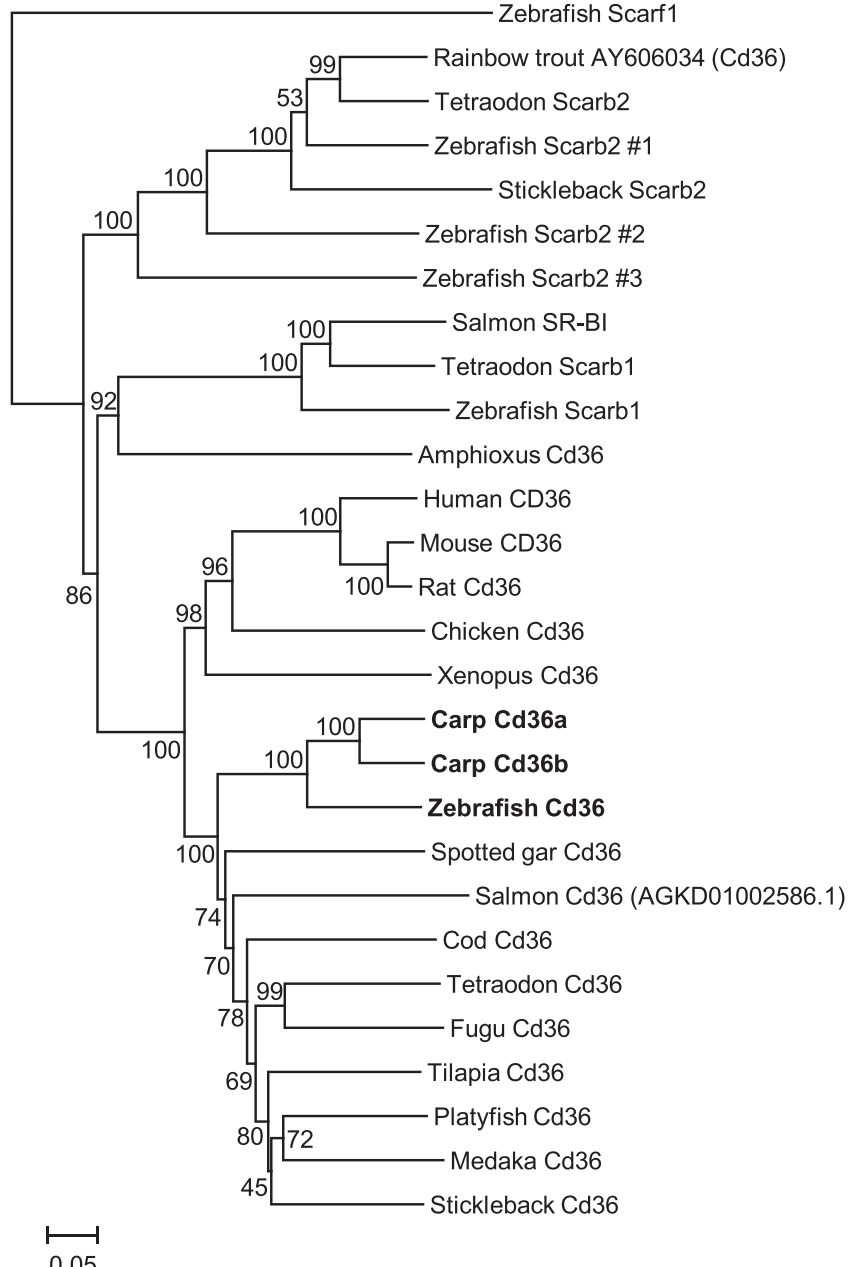

Fig. 3. Phylogenetic tree of $\mathrm{Cd} 36$ and Scarb sequences. Cd36, Scarb1 and Scarb2 molecules from various species were included in the phylogenetic analysis. A moderately related scavenger receptor (zebrafish Scarf1) was used as an outgroup. Carp Cd36a and Cd36b, as well as zebrafish Cd36 are indicated in bold. Amino acid sequences used: Zebrafish Scarf1 (Danio rerio ENSDARP00000113737), rainbow trout Cd36/Scarb2 (Oncorhynchus mykiss AY606034), tetraodon Scarb2 (Tetraodon nigroviridis ENSTNIP00000018658), zebrafish Scarb2 \#1 (Danio rerio ENSDARP00000110051), stickleback Scarb2 (Gasterosteus aculeatus ENSGACP00000018249), zebrafish Scarb2 \#2 (Danio rerio ENSDARP00000076810), zebrafish Scarb2 \#3 (Danio rerio ENSDARP00000110098), salmon SR-BI (Salmo salar DQ914655), tetraodon Scarb1 (Tetraodon nigroviridis ENSTNIP00000016587), zebrafish Scarb1 (Danio rerio ENSDARP00000106590), amphioxus Cd36 (Branchiostoma floridae JGI126670), human CD36 (Homo sapiens ENSP00000399421), mouse CD36 (Mus musculus ENSMUSP00000080974), rat Cd36 (Rattus norvegicus ENSRNOP00000058398), chicken Cd36 (Gallus gallus ENSGALP00000038958), xenopus Cd36 (Xenopus tropicalis ENSXETP00000017231), carp Cd36a (Cyprinus carpio KM030422), carp Cd36b (Cyprinus carpio Bioproject PRJNA73579), zebrafish Cd36 (Danio rerio ENSDARP00000050752), spotted gar Cd36 (Lepisosteus oculatus ENSLOCP00000019733), salmon Cd36 (Salmo salar, predicted from AGKD01002586.1), cod Cd36 (Gadus morhua ENSGMOP00000012522), tetraodon Cd36 (Tetraodon nigroviridis ENSTNIP00000014345), fugu Cd36 (Takifugu rubripes ENSTRUP00000041077), tilapia Cd36 (Oreochromis niloticus ENSONIP00000000108), platyfish Cd36 (Xiphophorus maculatus ENSXMAP00000004793), medaka Cd36 (Oryzias latipes ENSORLP00000020106), stickleback Cd36 (Gasterosteus aculeatus ENSGACP00000026370).

cd36 has been experimentally verified by CAGE analysis (personal communication, H.P. Spaink), while human, mouse and chicken transcriptional start sites and promoters are already annotated in MatInspector. The promoter analyses suggest regulation of $c d 36$ transcription by the common transcription factors Pu. 1 (part of the ETS family of transcription factors) (Zakrzewska et al., 2010), p53 (Lane and Levine, 2010), NF-kB (Oeckinghaus and Ghosh, 2009), and 
Table 2

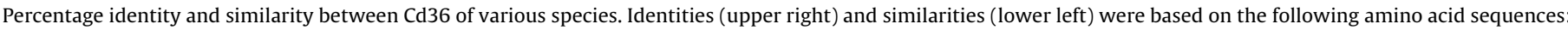

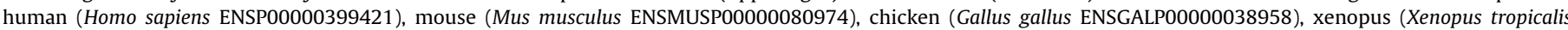

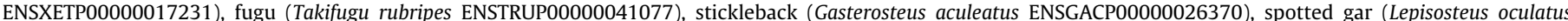

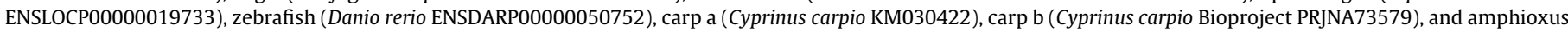
(Branchiostoma floridae JGI126670).

\begin{tabular}{|c|c|c|c|c|c|c|c|c|c|c|c|}
\hline & Human & Mouse & Chicken & Xenopus & Fugu & Stickleback & Spotted gar & Zebrafish & Carp a & Carp b & Amphioxus \\
\hline Human & & 84.1 & 61.4 & 54.9 & 52.3 & 51.1 & 51.6 & 51.5 & 51.2 & 50.8 & 35.6 \\
\hline Mouse & 94.1 & & 62.9 & 55.5 & 53.9 & 51.7 & 52.3 & 52.5 & 52.6 & 52.7 & 34.8 \\
\hline Chicken & 81.8 & 81.4 & & 56.2 & 49.8 & 50.9 & 51.7 & 52.9 & 51.5 & 50.1 & 36.9 \\
\hline Xenopus & 75.4 & 74.6 & 76 & & 50.8 & 52.2 & 51.4 & 51.2 & 49.3 & 47.1 & 36.8 \\
\hline Fugu & 72.8 & 72.6 & 72.8 & 71.6 & & 65.4 & 57.5 & 56.5 & 54.5 & 56.1 & 34.2 \\
\hline Stickleback & 73.5 & 72.5 & 71.5 & 72.3 & 80.2 & & 59.3 & 58.8 & 58.3 & 57.7 & 35.3 \\
\hline Spotted gar & 74 & 73.4 & 73.2 & 70.9 & 74.2 & 76.9 & & 56.3 & 56.1 & 57.5 & 37.2 \\
\hline Zebrafish & 73.1 & 71.6 & 74.3 & 70.2 & 74.9 & 77.4 & 73.4 & & 77.4 & 76.1 & 35.6 \\
\hline Carp a & 72.9 & 72.2 & 72 & 70.9 & 73.5 & 75.5 & 74 & 88.7 & & 87 & 37.3 \\
\hline Carp b & 73.1 & 72.5 & 73.2 & 70.9 & 75.2 & 76.5 & 75.5 & 88.7 & 93 & & 36.1 \\
\hline Amphioxus & 59.2 & 57.7 & 60 & 59.6 & 58.5 & 58.8 & 59.4 & 59 & 60.8 & 60.8 & \\
\hline
\end{tabular}

Human Chr. 7

Mouse Chr. 5

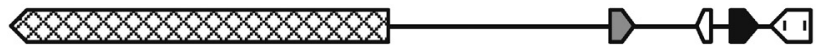

3.1 Mbp

Chicken Chr. 1

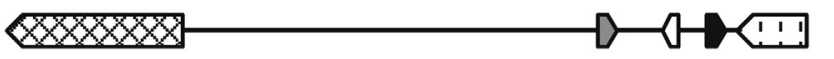

$1.4 \mathrm{Mbp}$

Xenopus Scaffold

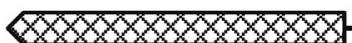

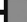

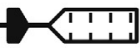

$0.75 \mathrm{Mbp}$ GL172681.1

Fugu Scaffold_21

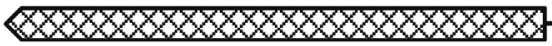

$0.12 \mathrm{Mbp}$

Stickleback Group IV

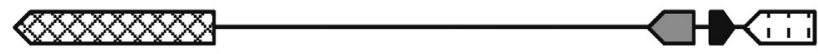

$0.15 \mathrm{Mbp}$

Spotted gar Chr. LG8

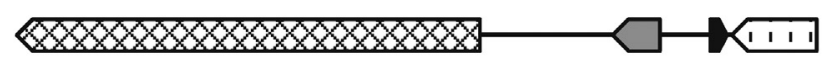

$0.66 \mathrm{Mbp}$

Zebrafish Chr. 4

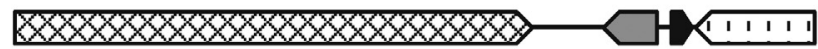

$0.50 \mathrm{Mbp}$

Carp Scaffold 349

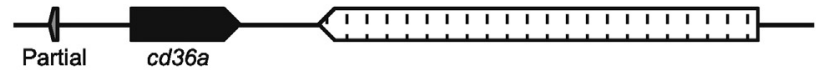

$0.05 \mathrm{Mbp}$

Carp Scaffolds 102854 and 15047

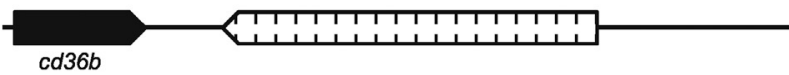

$0.05 \mathrm{Mbp}$

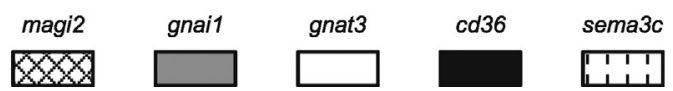

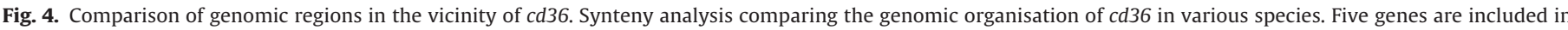

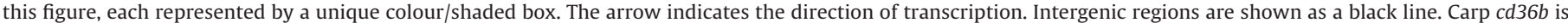
split over two scaffolds. The size of each depicted genomic area is indicated to the right, in megabasepairs (Mbp).

Stat1 (Reich, 2013). Although the exact locations of the transcription factor binding sites are not necessarily conserved and their functionality has not been experimentally verified, the presence of binding sites for all four transcription factors likely influences $c d 36$ gene expression levels in various tissues and cell types, including those with an immune function, and thus could be of importance for Cd36 function.

\subsection{Gene expression}

Constitutive gene expression of $c c c d 36 a$ and $c c c d 36 b$ was measured in organs of four healthy carp and normalized to the expression of the housekeeping gene. The results from 15 organs are shown in Fig. 5A. The gene expression of cccd36a is generally higher than that of $c c c d 36 b$. Highest expression for both genes 
A
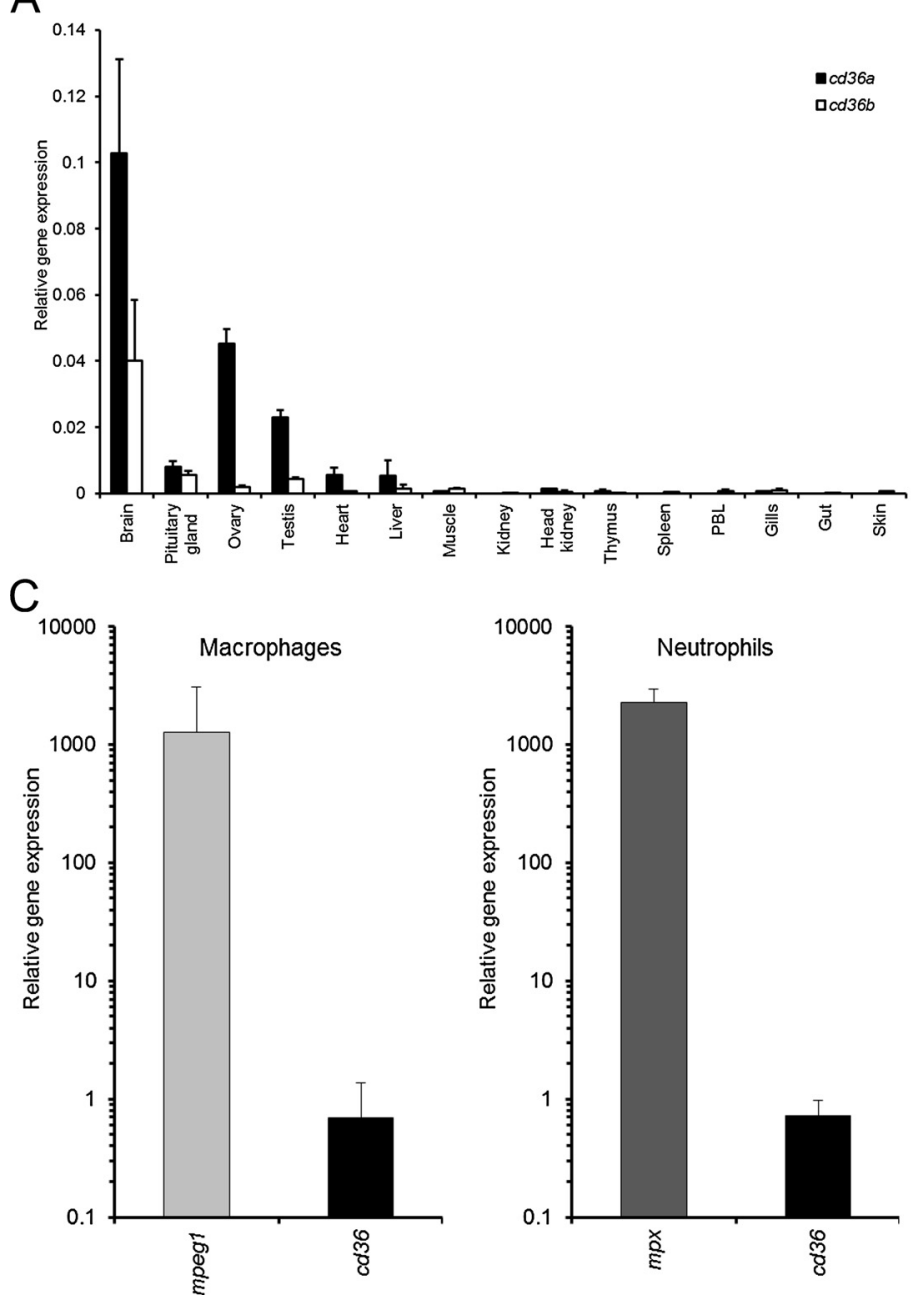

B

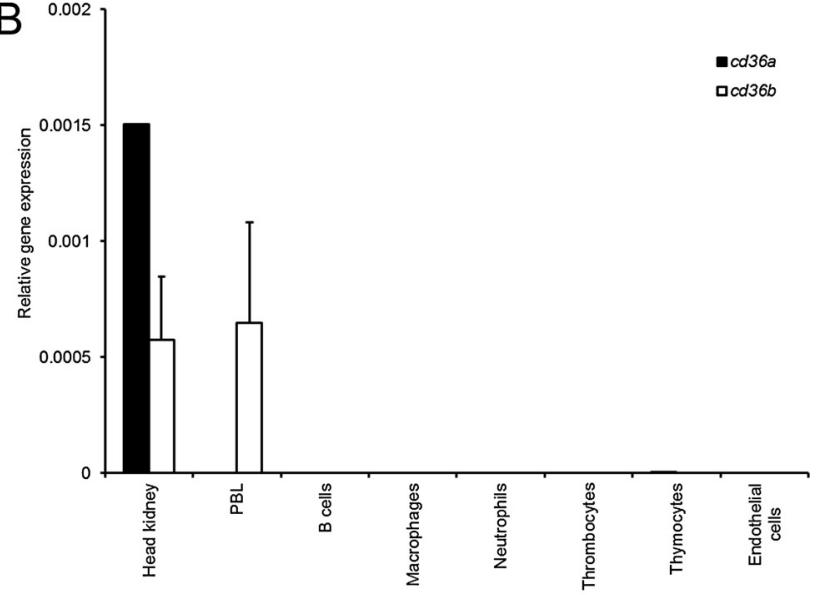

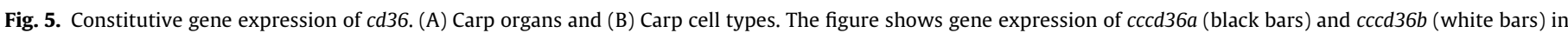

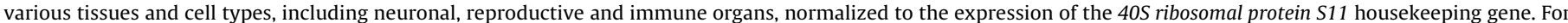

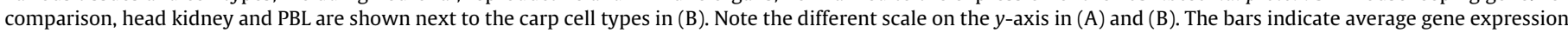

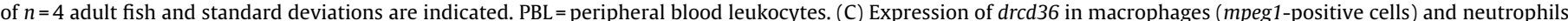

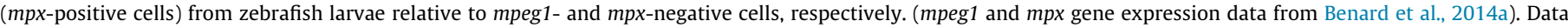
represent $n=3$ biological replicates and are normalized to the eif 4 housekeeping gene.

is found in brain tissue $(0.10$ and 0.04 times the housekeeping gene, respectively), with the pituitary gland contributing slightly to the total brain gene expression. High-to-moderate gene expression was also detected in the reproductive organs, ovary ( 0.05 and 0.002 ) and testis (0.02 and 0.004$)$, followed by low-to-moderate expression $(\leq 0.005)$ levels in heart and liver. The remaining organs, including typical immune organs such as head kidney and spleen, have a very low to undetectable $c d 36$ gene expression level. The relatively high gene expression in brain, ovary and testis, and low to non-detectable expression in other tissues including the immune organs tested was confirmed by transcriptome analysis of the same organs from carp (data not shown). In addition, several primer pairs were used for RT-qPCR yielding similar results. The sequences of these primers are listed in Table 1, and their location is shown in Supplementary Fig. 2. Furthermore, $c d 36$ gene expression was undetectable by RT-qPCR using as template various immune cell types from carp purified by magnetically activated cell sorting (MACS), i.e. thrombocytes, thymocytes, neutrophils, B cells, and macrophages (Fig. 5B).

Complementary to the analysis of multiple organs and cell types of adult carp, we took advantage of the zebrafish model to investigate $c d 36$ expression in leukocytes. To this end we used transgenic zebrafish lines with different fluorescently marked leukocyte populations, dissociated larvae at $6 \mathrm{dpf}$ and isolated the fluorescent and non-fluorescent cell fractions by fluorescence activated cell sorting (FACS). RT-qPCR analysis of FACS isolated macrophages (mpeg1promoter driven fluorescence) and neutrophils ( $m p x$-promoter driven fluorescence) from zebrafish $6 \mathrm{dpf}$ larvae revealed a very low cd36 gene expression compared to the levels of macrophageor neutrophil-specific markers (mpeg1 and $m p x$, respectively), as shown in Fig. 5C.

\subsection{Subcellular localization}

In order to investigate the subcellular localization of cyprinid Cd36 we first cloned and sequenced the full-length cccd36a coding region. We then transfected the HEK cell line with a construct expressing carp Cd36a fused to the fluorescent protein mCherry. The cell membrane was visualized by staining with wheat germ agglutinin-Alexa 488 conjugate which exhibits green fluorescence. Confocal microscopy showed the presence of Cd36a-mCherry at the rim of the cells, co-localizing with the green fluorescent surface stain (Fig. 6A). In contrast, the fluorescent protein mCherry alone does not localize to the cell membrane but is evenly 

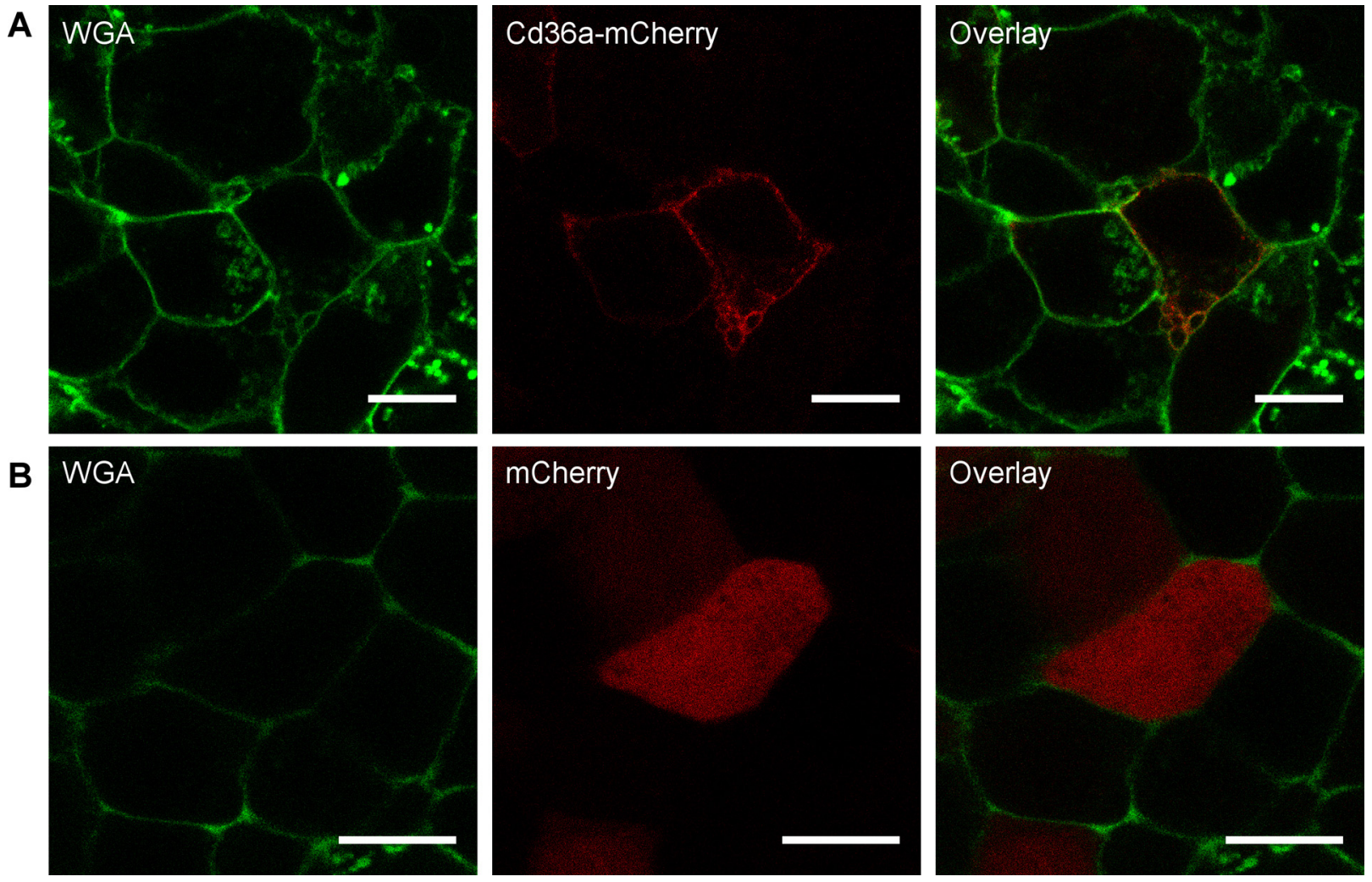

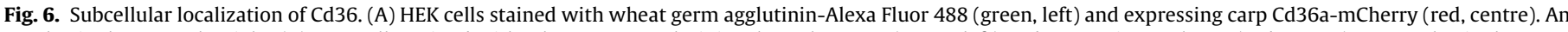

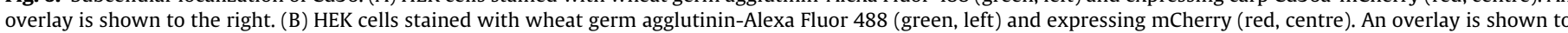
the right. (For interpretation of the references to color in this figure legend, the reader is referred to the web version of this article.)

distributed throughout the cell (Fig. 6B), meaning the Cd36 molecule is responsible for the redirection of the fluorescent protein to the cell membrane. Similar results were obtained with EPC cells transfected with the same Cd36 construct (data not shown). The surface localization of carp Cd36a is in agreement with the localization of the mammalian $\mathrm{Cd} 36$ molecule as well as the predicted structure of the carp molecule with two transmembrane regions, an extracellular part, and two cytoplasmic tails.

\subsection{Role of Cd36 in M. marinum infection}

To further study the function of teleost Cd36, we took advantage of the rapid gene knockdown technology available for zebrafish (Sumanas and Larson, 2002). We used antisense morpholino oligonucleotides to knockdown cd36 in zebrafish embryos, which were subsequently subjected to infection with mCherry-labelled M. marinum. The bacterial fluorescence per embryo was quantified at $4 \mathrm{dpi}$ by image analysis. At this stage of $M$. marinum infection, the embryos have developed granuloma-like structures consisting of infected and uninfected leukocytes and the bacterial fluorescence within these granulomas can be detected with stereo fluorescence microscopy (Benard et al., 2012). Two different splice blocking morpholinos were used targeting different exonintron splice junctions of the cd36 gene. The knockdown effect was verified by RT-PCR (Supplementary Fig. 3) and embryos were stained with antibody against the pan-leukocytic marker L-plastin, showing that $c d 36$ knockdown did not affect leukocyte development in duct of Cuvier or in the tail region (Supplementary Fig. 4). Both $c d 36$ morphant groups showed a significantly increased bacterial fluorescence compared to embryos injected with a control morpholino (quantification shown in Fig. 7A, and representative pictures shown in Fig. 7B). We further analysed gene expression of cd36 in M. marinum-infected zebrafish embryos at 4 dpi (Fig. 7C). Compared to uninfected fish, $c d 36$ expression was down-regulated approximately 3 -fold in infected individuals.

\section{Discussion}

Given our interest in the function of TLRs and the evidence, at least in mammals, of CD36 interaction with preformed TLR2TLR6 heterodimers, we aimed to characterize the function of Cd36 in zebrafish and common carp, two closely related cyprinid fish species. Cyprinid Cd36 molecules are integral membrane glycoproteins with two transmembrane domains, a large extracellular loop and two short intracellular tails and are similar to mammalian Cd36 at the sequence level. Similar to mammalian Cd36 proteins the disulphide bonds are conserved in the cyprinid proteins, and so is the presence of multiple $\mathrm{N}$-glycosylation sites. At present, immune functions for the scavenger receptor class B family member Cd36 have not been described for teleost fish.

Although the cyprinid Cd36 sequences seem relatively similar to mammalian Cd36, there also appear to be a number of intriguing differences. In contrast to the human protein that has no $O$-glycosylation sites, there is one $O$-glycosylation site predicted in $\mathrm{drCd} 36$, three sites in ccCd36a, and one site in ccCd36b. The significance of these potential $O$-glycosylation sites in the fish $\mathrm{Cd} 36$ proteins is not known. Most notably, there is a clear difference between the mammalian and fish $\mathrm{Cd} 36$ sequences in the $\mathrm{C}$-terminal tail which, at least in the human protein, contains two key amino acids, namely Y463 and C464. The cysteine is palmitoylated and plays a role in the localization of $\mathrm{Cd} 36$ to lipid raft domains in the plasma membrane (Tao et al., 1996), whereas the tyrosine is a potential site of phosphorylation and could provide a docking site for SH2 domain-containing proteins such as the Src family 
A

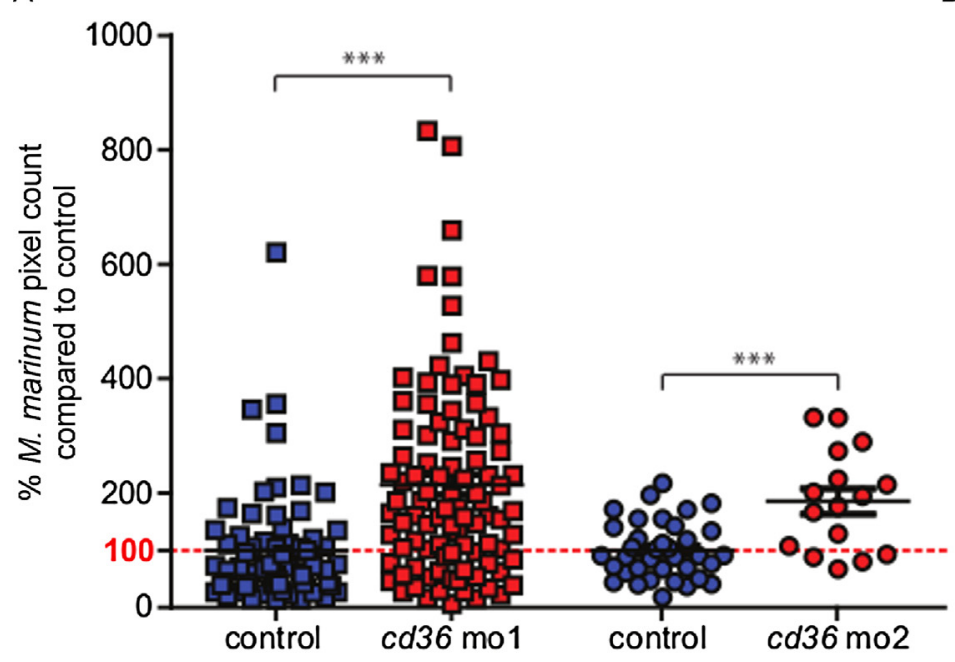

B
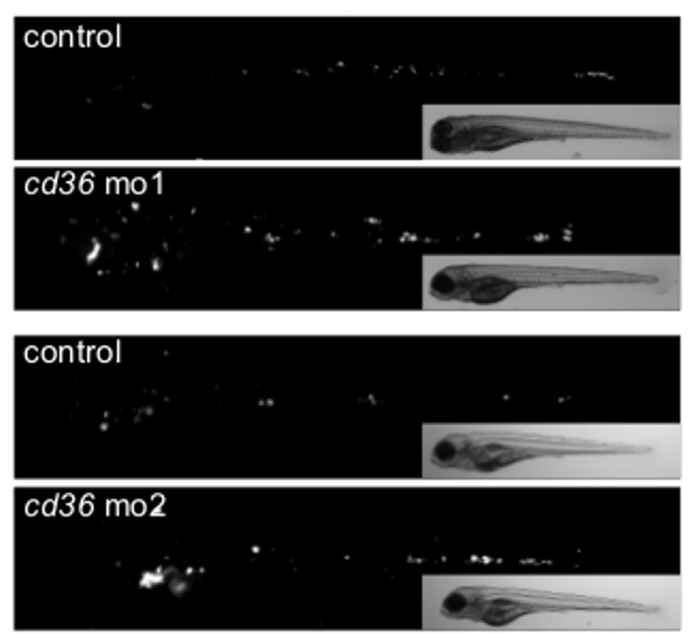

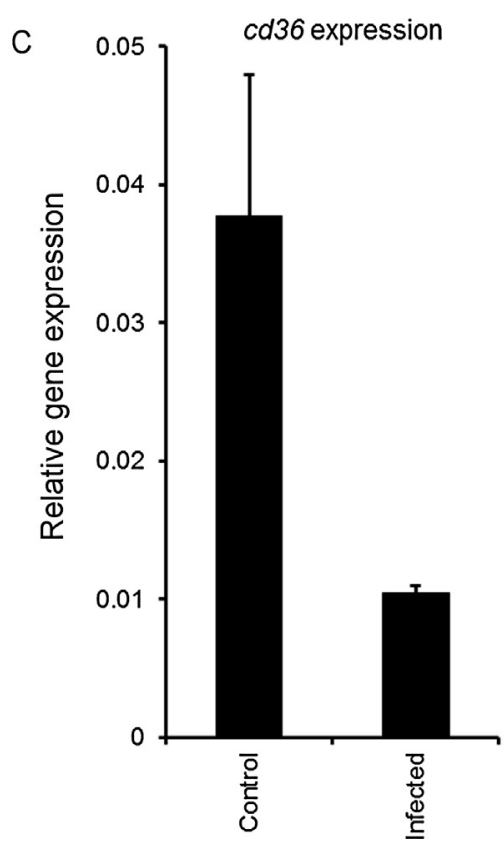

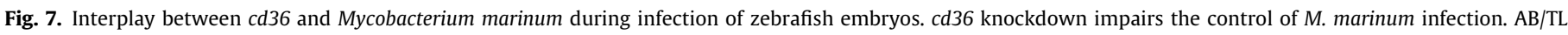

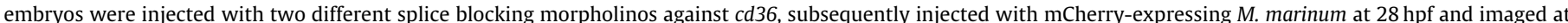

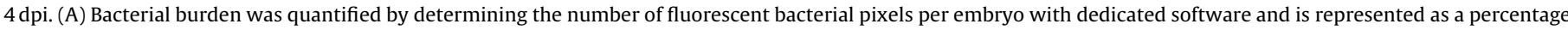

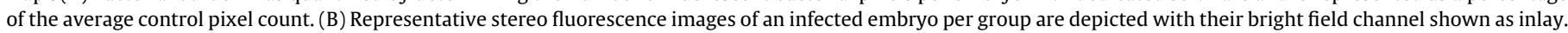

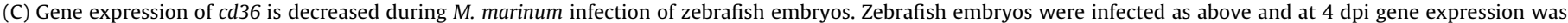
analysed for $c d 36$ and normalized to the ppial housekeeping gene. Data represent the average and standard deviation obtained from $n=3$ biological replicates.

of tyrosine kinases and the actin regulator p130Cas (Stuart et al., 2005). Src kinases that reside in lipid rafts have previously been shown to initiate downstream signalling cascades upon interaction with $\mathrm{Cd} 36$, and the actin regulator p130Cas is presumably involved in Cd36-dependent cytoskeletal rearrangements that are required for phagocytosis (Stuart et al., 2007). Upon examination of the Cterminal tail of cyprinid $\mathrm{Cd} 36$ molecules it is clear that no tyrosine is present but a single cysteine is found. Possibly, the presence of the cysteine could suggest that cyprinid Cd36 may localize to lipid rafts in the plasma membrane, but the absence of the tyrosine could have a determining effect on signalling and phagocytosis.

In our study we could demonstrate the presence of $\mathrm{Cd} 36$ on the plasma membrane by confocal microscopy. We could not clearly demonstrate, however, a role for Cd36 in phagocytosis; morpholino knockdown of zebrafish cd36 did not affect phagocytosis of M. marinum (Benard et al., 2014b) and transfection of cell lines with carp cd36 did not confer the ability to phagocytose $S$. aureus or zymosan particles (unpublished data, I. R. Fink). This suggests that differences in key amino acids in the C-terminal tail of cyprinid Cd36 may affect function of fish $\mathrm{Cd} 36$ as compared to function of mammalian Cd36.

We further used cell lines transfected with carp cd36 to study its putative role as a pattern recognition receptor, by stimulating the cells with various ligands and measuring downstream transcription factor activation. Since we could not see any effect of $c d 36$ in these studies, this could indicate that $c d 36$ might primarily function as a co-receptor and as such would always require the presence of another receptor to fulfil its role.

High gene expression levels of cyprinid cd36 were found in brain, ovary and testis. In contrast, gene expression was undetectable in immune organs and undetectable in all leukocyte subtypes tested, including monocytes/macrophages of adult carp. 
Also macrophages and neutrophils from zebrafish larvae had very low levels of $c d 36$ expression. In mammals, $c d 36$ is expressed in many different tissues and cell types, e.g. skeletal and smooth muscle, intestinal epithelia, adipocytes, endothelial cells, platelets, dendritic cells and monocytes/macrophages (Febbraio et al., 2001). We refute the option that the surprising absence of $c d 36$ gene expression in immune organs and cell types from (cyprinid) fish could be due to the design of our primers; design of several additional primer pairs located in different parts of $c d 36$ did not provide any indication of $c d 36$ expression in immune organs and immune cell types. We consider it unlikely that all the primer combinations we tested for carp cd36 would have failed to amplify particular truncated splice variants uniquely expressed in immune organs and immune cell types. Although our primers would not detect the possible existence of tissue-specific splice variants arising from alternative promoter usage (Andersen et al., 2006), CAGE analysis indicates the presence of only a single transcription start site for zebrafish $c d 36$, which suggests tissue-specific splice variants of cd36 may not be commonly seen in fish. Furthermore, transcriptome analyses of a multitude of carp organs revealed an expression pattern for $c d 36$ which confirms our findings (unpublished data). In fact, we have found no indication for alternative splicing of cyprinid cd36. Possibly, differences in transcriptional regulation of cd36 and/or absence of splice variants in cyprinid cd36 molecules might help explain differences in function between mammalian and fish Cd36. Of interest, particular mutations in the human cd36 gene can give rise to aberrant expression patterns and phenotypes. One example is a rather commonly occurring mutation (C268T), which leads to lack of $c d 36$ expression in monocytes and platelets, a condition called type I deficiency (Rac et al., 2007). Although this particular nucleotide is not mutated in the cyprinid genes and thus does not explain the observed absence of $c d 36$ gene expression in these cell types in fish, clearly mammalian CD36 is prone to mutations that affect expression in monocytes and platelets, a phenotype comparable to what we observe in the teleosts we studied. In conclusion, the complete absence of $c d 36$ gene expression in immune organs and leukocyte cell types of cyprinid fish suggests that maybe not all prototypical immune functions ascribed to the function of CD36 as a PRR important in innate immunity would be present in (cyprinid) fish. Clearly, the exact function of fish Cd36 remains a subject of investigation.

Presence of high levels of cyprinid cd36 gene expression particularly in brain, testis and ovary, tissues with high lipid and/or cholesterol uptake for e.g. conversion to neurosteroid and sex hormones, could be indicative of a function for $\mathrm{Cd} 36$ mediating cholesterol transfer, a normal characteristic of the Scarb1 protein, in particular. Previous studies in salmon and rainbow trout (Trattner et al., 2008; Torstensen et al., 2011; Sanchez-Gurmaches et al., 2012, and others) on Cd36 have pointed to lipid metabolism as a function conserved between mammalian and teleost $\mathrm{Cd} 36$. Although it may well be true that fish members of the class B family of scavenger receptors, including Cd36 and Scarb molecules have overlapping functions, our phylogenetic analysis shows that the rainbow trout Cd36 sequence is more likely a Scarb2 homolog, which would suggest these data have to be interpreted with care. Although we identified a putative $\mathrm{Cd} 36$ sequence in salmon that also exhibits conserved synteny and does cluster with other fish Cd36 sequences in the phylogenetic tree, we could not easily identify a $c d 36$ sequence in rainbow trout. In fact all candidates in rainbow trout are more closely related to Scarb2 molecules than to Cd36. Several scarb1 and scarb2 paralogs are present in both the zebrafish and carp genome and interestingly, in contrast to $c d 36$, transcriptome data reveal moderate to high expression of both scarb1 and scarb2 genes in macrophages (unpublished data, I. R. Fink). This finding reinforces the possibility that the division of functions between members of the class B family of scavenger receptors could be different between mammals and fish.

The ancestral $c d 36$ gene in amphioxus could be up-regulated by in vivo challenge with $E$. coli, and by in vitro LTA stimulation of a flounder cell line transfected with an amphioxus cd36-pcDNA3 construct (Zhang et al., 2013). However, our in vivo study showed that cd36 gene expression in M. marinum-infected zebrafish embryos was down-regulated, which is in line with published data on infected adult zebrafish (van der Sar et al., 2009).

Although a null mutant would be required to confirm our results, knockdown of $c d 36$ in zebrafish embryos did not affect general development of leukocytes or the migration of neutrophils or macrophages towards locally induced inflammation, nor phagocytosis of $M$. marinum but did result in higher bacterial load following infection with $M$. marinum, suggesting a possible but presently undefined role for fish $\mathrm{Cd} 36$ in the control of bacterial infection. Given the suggestion that the division of functions between members of the class B family of scavenger receptors could be different between mammals and fish, future studies could address immune functions of the different class B family members found in teleost fish and explore further their functional relationships.

\section{Acknowledgements}

We thank Fons Verbeek and Alexander Nezhinsky (Leiden University, The Netherlands) for making an improved version of the pixel quantification software available prior to publication. The research leading to these results has received funding from the European Commission under the 7th Framework Programme for Research and Technological Development (FP7) of the European Union (grant agreement NEMO PITN-GA-2008-214505) to IRF and GFW. ELB and AHM were supported by the Smart Mix Program of the Netherlands Ministry of Economic Affairs and the Ministry of Education, Culture and Science.

\section{Appendix A. Supplementary data}

Supplementary data associated with this article can be found, in the online version, at http://dx.doi.org/10.1016/ j.molimm.2014.09.010.

\section{References}

Abumrad, N.A., El-Maghrabi, M.R., Amri, E.Z., Lopez, E., Grimaldi, P.A., 1993. Cloning of a rat adipocyte membrane protein implicated in binding or transport of longchain fatty acids that is induced during preadipocyte differentiation. Homology with human CD36. J. Biol. Chem. 268, 17665-17668.

Akira, S., Takeda, K., 2004. Toll-like receptor signalling. Nat. Rev. Immunol. 4, 499-511.

Andersen, M., Lenhard, B., Whatling, C., Eriksson, P., Odeberg, J., 2006. Alternative promoter usage of the membrane glycoprotein CD36. BMC Mol. Biol. 7, 8.

Benard, E.L., Racz, P.I., Rougeot, J., Nezhinsky, A.E., Verbeek, F.J., Spaink H.P., Meijer, A.H., 2014a. Macrophage-expressed perforins Mpeg1 and Mpeg1.2 have an anti-bacterial function in zebrafish. J. Innate. Immun. http://dx.doi.org/10.1159/000366103.

Benard, E.L., Roobol, S.J., Spaink, H.P., Meijer, A.H., 2014b. Phagocytosis of mycobacteria by zebrafish macrophages is dependent on the scavenger receptor Marco, a key control factor of pro-inflammatory signalling. Dev. Comp. Immunol. 47, 223-233.

Benard, E.L., van der Sar, A.M., Ellett, F., Lieschke, G.J., Spaink, H.P., Meijer, A.H., 2012. Infection of zebrafish embryos with intracellular bacterial pathogens. J. Visualized Exp.: JoVE 61, e3781.

Bernut, A., Herrmann, J.L., Kissa, K., Dubremetz, J.F., Gaillard, J.L., Lutfalla, G., Kremer L., 2014. Mycobacterium abscessus cording prevents phagocytosis and promotes abscess formation. Proc. Natl. Acad. Sci. U.S.A. 111, E943-E952.

Brundert, M., Ewert, A., Heeren, J., Behrendt, B., Ramakrishnan, R., Greten, H., Merkel, M., Rinninger, F., 2005. Scavenger receptor class B type I mediates the selective uptake of high-density lipoprotein-associated cholesteryl ester by the liver in mice. Arterioscler. Thromb. Vasc. Biol. 25, 143-148.

Calvo, D., Dopazo, J., Vega, M.A., 1995. The CD36, CLA-1 (CD36L1), and LIMPII (CD36L2) gene family: cellular distribution, chromosomal location, and genetic evolution. Genomics 25, 100-106. 
Calvo, D., Vega, M.A., 1993. Identification, primary structure, and distribution of CLA-1, a novel member of the CD36/LIMPII gene family. J. Biol. Chem. 268, 18929-18935.

Chadwick, A.C., Sahoo, D., 2013. Functional genomics of the human high-density lipoprotein receptor scavenger receptor BI: an old dog with new tricks. Curr. Opin. Endocrinol. Diabetes Obes. 20, 124-131.

Covassin, L., Amigo, J.D., Suzuki, K., Teplyuk, V., Straubhaar, J., Lawson, N.D., 2006. Global analysis of hematopoietic and vascular endothelial gene expression by tissue specific microarray profiling in zebrafish. Dev. Biol. 299, $551-562$.

Endemann, G., Stanton, L.W., Madden, K.S., Bryant, C.M., White, R.T., Protter, A.A., 1993. CD36 is a receptor for oxidized low density lipoprotein. J. Biol. Chem. 268, $11811-11816$

Febbraio, M., Hajjar, D.P., Silverstein, R.L., 2001. CD36: a class B scavenger receptor involved in angiogenesis, atherosclerosis, inflammation, and lipid metabolism. J. Clin. Invest. 108, 785-791.

Forlenza, M., Scharsack, J.P., Kachamakova, N.M., Taverne-Thiele, A.J., Rombout, J.H., Wiegertjes, G.F., 2008. Differential contribution of neutrophilic granulocytes and macrophages to nitrosative stress in a host-parasite animal model. Mol. Immunol. 45, 3178-3189.

Gonzalez, A., Valeiras, M., Sidransky, E., Tayebi, N., 2014. Lysosomal integral membrane protein-2: a new player in lysosome-related pathology. Mol. Genet. Metab. 111, 84-91.

Greenwalt, D.E., Watt, K.W., Hasler, T., Howard, R.J., Patel, S., 1990. Structural, functional, and antigenic differences between bovine heart endothelial CD36 and human platelet CD36. J. Biol. Chem. 265, 16296-16299.

Henkel, C.V., Dirks, R.P., Jansen, H.J., Forlenza, M., Wiegertjes, G.F., Howe, K., van den Thillart, G.E., Spaink, H.P., 2012. Comparison of the exomes of common carp (Cyprinus carpio) and zebrafish (Danio rerio). Zebrafish 9, 59-67.

Hoebe, K., Georgel, P., Rutschmann, S., Du, X., Mudd, S., Crozat, K., Sovath, S., Shamel, L., Hartung, T., Zähringer, U., Beutler, B., 2005. CD36 is a sensor of diacylglycerides. Nature $433,523-527$.

Irnazarow, I., 1995. Genetic variability of Polish and Hungarian carp lines. Aquaculture 129, 215-219.

Koumans-van Diepen, J.C.E., Egberts, E., Peixoto, B.R., Taverne, N., Rombout, J.H.W.M., 1995. B cell and immunoglobulin heterogeneity in carp (Cyprinus carpio L.); an immuno(cyto)chemical study. Dev. Comp. Immunol. 19, 97-108.

Lane, D., Levine, A., 2010. p53 Research: the past thirty years and the next thirty years. Cold Spring Harbor Perspect. Biol. 2, a000893.

Larkin, M.A., Blackshields, G., Brown, N.P., Chenna, R., McGettigan, P.A., McWilliam, H., Valentin, F., Wallace, I.M., Wilm, A., Lopez, R., Thompson, J.D., Gibson, T.J., Higgins, D.G., 2007. Clustal W and Clustal X version 2.0. Bioinformatics 23, 2947-2948.

Lee, C.C., Avalos, A.M., Ploegh, H.L., 2012. Accessory molecules for Toll-like receptors and their function. Nat. Rev. Immunol. 12, 168-179.

Mathias, J.R., Dodd, M.E., Walters, K.B., Rhodes, J., Kanki, J.P., Look, A.T., Huttenlocher, A., 2007. Live imaging of chronic inflammation caused by mutation of zebrafish Hai1. J. Cell Sci. 120, 3372-3383.

Means, T.K., Mylonakis, E., Tampakakis, E., Colvin, R.A., Seung, E., Puckett, L., Tai, M.F., Stewart, C.R., Pukkila-Worley, R., Hickman, S.E., Moore, K.J., Calderwood, S.B., Hacohen, N., Luster, A.D., El Khoury, J., 2009. Evolutionarily conserved recognition and innate immunity to fungal pathogens by the scavenger receptors SCARF1 and CD36. J. Exp. Med. 206, 637-653.

Nezhinsky, A.E., Stoop, E., van der Sar, A., Verbeek, F.J., 2012. Numerical Analysis of Image Based High Throughput Zebrafish Infection Screens-Matching Meaning with Data., pp. 257-262

Oeckinghaus, A., Ghosh, S., 2009. The NF-кB family of transcription factors and its regulation. Cold Spring Harbor Perspect. Biol. 1, a000034.

Pietretti, D., Spaink, H.P., Falco, A., Forlenza, M., Wiegertjes, G.F., 2013. Accessory molecules for Toll-like receptors in teleost fish. Identification of TLR4 interactor with leucine-rich repeats (TRIL). Mol. Immunol. 56, 745-756.

Pietretti, D., Wiegertjes, G.F., 2014. Ligand specificities of Toll-like receptors in fish: indications from infection studies. Dev. Comp. Immunol. 43, 205-222.

Plüddemann, A., Neyen, C., Gordon, S., 2007. Macrophage scavenger receptors and host-derived ligands. Methods 43, 207-217

Rac, M.E., Safranow, K., Poncyljusz, W., 2007. Molecular basis of human CD36 gene mutations. Mol. Med. 13, 288-296.

Reich, N.C., 2013. STATs get their move on. Jak-Stat 2, e27080.

Renshaw, S.A., Loynes, C.A., Trushell, D.M.I., Elworthy, S., Ingham, P.W., Whyte, M.K.B., 2006. A transgenic zebrafish model of neutrophilic inflammation. Blood 108, 3976-3978.

Ribeiro, C.M., Hermsen, T., Taverne-Thiele, A.J., Savelkoul, H.F., Wiegertjes, G.F., 2010. Evolution of recognition of ligands from Gram-positive bacteria: similarities and differences in the TLR2-mediated response between mammalian vertebrates and teleost fish. J. Immunol. 184, 2355-2368.
Romano, N., Picchietti, S., Taverne-Thiele, J.J., Taverne, N., Abelli, L., Mastrolia, L., Verburg-van Kemenade, B.M.L., Rombout, J.H.W.M., 1998. Distribution of macrophages during fish development: an immunohistochemical study in carp (Cyprinus carpio, L.). Anat. Embryol. 198, 31-41.

Rombout, J.H.W.M., Koumans-van Diepen, J.C.E., Emmer, P.M., Taverne-Thiele, J.J., Taverne, N., 1996. Characterization of carp thrombocytes with specific monoclonal antibodies. J. Fish Biol. 49, 521-531.

Sanchez-Gurmaches, J., Cruz-Garcia, L., Gutierrez, J., Navarro, I., 2012. mRNA expression of fatty acid transporters in rainbow trout: in vivo and in vitro regulation by insulin, fasting and inflammation and infection mediators. Comp. Biochem. Physiol. A: Mol. Integr. Physiol. 163, 177-188.

Sanchez-Gurmaches, J., Østbye, T.-K., Navarro, I., Torgersen, J., Hevrøy, E.M., Ruyter, B., Torstensen, B.E., 2011. In vivo and in vitro insulin and fasting control of the transmembrane fatty acid transport proteins in Atlantic salmon (Salmo salar). Am. J. Physiol. Regul. Integr. Comp. Physiol. 301, R947-R957.

Secombes, C.J., van Groningen, J.J.M., Egberts, E., 1983. Separation of lymphocyte subpopulations in carp Cyprinus carpio L. by monoclonal antibodies: immunohistochemical studies. Immunol. 48, 165-175.

Shu, G., Liao, W.Y., Feng, J.Y., Yu, K.F., Zhai, Y.F., Wang, S.B., Khondowe, P., Wang, X.Q., Jiang, Q.Y., 2011. Active immunization of fatty acid translocase specifically decreased visceral fat deposition in male broilers. Poult. Sci. 90, 2557-2564.

Silverstein, R.L., Febbraio, M., 2009. CD36, a scavenger receptor involved in immunity, metabolism, angiogenesis, and behavior. Sci. Signal. 2, re3.

Stockhammer, O.W., Zakrzewska, A., Hegedus, Z., Spaink, H.P., Meijer, A.H., 2009 Transcriptome profiling and functional analyses of the zebrafish embryonic innate immune response to Salmonella infection. J. Immunol. 182, 5641-5653.

Stolte, E.H., Savelkoul, H.F., Wiegertjes, G., Flik, G., Lidy Verburg-van Kemenade, B.M., 2008. Differential expression of two interferon- $\gamma$ genes in common carp (Cyprinus carpio L.). Dev. Comp. Immunol. 32, 1467-1481.

Stoop, E.J.M., Schipper, T., Rosendahl Huber, S.K., Nezhinsky, A.E., Verbeek, F.J., Gurcha, S.S., Besra, G.S., Vandenbroucke-Grauls, C.M.J.E., Bitter, W., van der Sar, A.M. 2011. Zebrafish embryo screen for mycobacterial genes involved in the initiation of granuloma formation reveals a newly identified ESX-1 component. Dis. Models Mech. 4, 526-536.

Stuart, L.M., Bell, S.A., Stewart, C.R., Silver, J.M., Richard, J., Goss, J.L., Tseng, A.A. Zhang, A., El Khoury, J.B., Moore, K.J., 2007. CD36 signals to the actin cytoskeleton and regulates microglial migration via a p130Cas complex. J. Biol. Chem. 282 27392-27401

Stuart, L.M., Deng, J., Silver, J.M., Takahashi, K., Tseng A.A., Hennessy, E.J., Ezekowitz R.A., Moore, K.J., 2005. Response to Staphylococcus aureus requires CD36mediated phagocytosis triggered by the COOH-terminal cytoplasmic domain. J. Cell Biol. 170, 477-485.

Sumanas, S., Larson, J.D., 2002. Morpholino phosphorodiamidate oligonucleotides in zebrafish: a recipe for functional genomics? Brief Funct. Genomic Proteomic $1,239-256$.

Tao, N., Wagner, S.J., Lublin, D.M., 1996. CD36 is palmitoylated on both N- and Cterminal cytoplasmic tails. J. Biol. Chem. 271, 22315-22320.

Torstensen, B.E., Espe, M., Stubhaug, I., Lie, O., 2011. Dietary plant proteins and vegetable oil blends increase adiposity and plasma lipids in Atlantic salmon (Salmo salar L.). Br. J. Nutr. 106, 633-647.

Trattner, S., Ruyter, B., Ostbye, T.K., Gjoen, T., Zlabek, V., Kamal-Eldin, A., Pickova, J., 2008. Sesamin increases alpha-linolenic acid conversion to docosahexaenoic acid in atlantic salmon (Salmo salar L.) hepatocytes: role of altered gene expression. Lipids 43, 999-1008.

Triantafilou, M., Gamper, F.G., Haston, R.M., Mouratis, M.A., Morath, S., Hartung, T., Triantafilou, K., 2006. Membrane sorting of toll-like receptor (TLR)-2/6 and TLR2/1 heterodimers at the cell surface determines heterotypic associations with CD36 and intracellular targeting. J. Biol. Chem. 281, 31002-31011.

van der Sar, A.M., Abdallah, A.M., Sparrius, M., Reinders, E., Vandenbroucke-Grauls, C.M., Bitter, W., 2004. Mycobacterium marinum strains can be divided into two distinct types based on genetic diversity and virulence. Infect. Immun. 72, 6306-6312.

van der Sar, A.M., Spaink, H.P., Zakrzewska, A., Bitter, W., Meijer, A.H., 2009 Specificity of the zebrafish host transcriptome response to acute and chronic mycobacterial infection and the role of innate and adaptive immune components. Mol. Immunol. 46, 2317-2332.

Verburg-van Kemenade, B.M.L., Groeneveld, A., van Rens, B.T.T.M., Rombout, J.H.W.M., 1994. Characterization of macrophages and neutrophilic granulocytes from the pronephros of carp (Cyprinus carpio). J. Exp. Biol. 187, 143-158.

Zakrzewska, A., Cui, C., Stockhammer, O.W., Benard, E.L., Spaink, H.P., Meijer, A.H., 2010. Macrophage-specific gene functions in Spi1-directed innate immunity. Blood 116, e1-e11.

Zhang, M., Xu, Y., Li, L., Wei, S., Zhang, S., Liu, Z., 2013. Identification, evolution and expression of a CD36 homolog in the basal chordate amphioxus Branchiostoma japonicum. Fish Shellfish Immunol. 34, 546-555. 